\title{
Öğretmenlerin Duygusal Zekâları ile Sınıf Yönetim Becerileri Arasındaki İlişkide Öz Yeterlik İnancının Aracılık Rolü*
}

\author{
Hediye SAĞLAM** Hasan KAVGACI ${ }^{* * *}$
}

- Geliş Tarihi: 29.07.2020 • Kabul Tarihi: 08.01.2021 • Çevrimiçi Yayın Tarihi: 09.01.2021

\section{$\ddot{\mathbf{O z}}$}

$\mathrm{Bu}$ araştırmanın amacı okulöncesi ve ilköğretim öğretmenlerinin duygusal zekâları ile sınıf yönetim becerileri arasındaki ilişkilerin ve bu ilişkide öz yeterlik inancının aracılık rolünün incelenmesidir. Nicel araştırma deseninde kurgulanan araştırmada ilişkisel tarama modeli kullanılmıştır. Araştırmanın çalışma grubunu 376 anasınıfı, ilk ve ortaokul öğretmeni oluşturmaktadır. Yaş ortalamaları $37(S D=8,7)$ olan katılımc1ların \%68'i kadın, \%32'si erkektir. Veri toplama aracı olarak; Kişisel Bilgi Formu, Sınıf Yönetim Becerileri Ölçeği, Duygusal Zekâ Ölçeği ve Öğretmen Öz Yeterlik İnancı Ölçeği kullanılmıştır. Veriler SPSS-21 paket programı kullanılarak analiz edilmiştir. Araştırmada değişkenler arası ilişkileri belirlemek amacıyla Pearson Momentler Korelasyon Katsayıları hesaplanmış, yordama durumunu incelemek için ise Çoklu Regresyon Analizi yapılmıştır. Araştırmada aracılık etkisi SPSS-PROCESS makrosu kullanılarak analiz edilmiştir. Araştırma bulguları değerlendirildiğinde değişkenler arasında orta düzeyde, pozitif ve anlamlı ilişkiler elde edilmiştir. Ayrıca duygusal zekâ ve öz yeterlik inancının öğretmenlerin sınıf yönetim becerilerinin \% 48'ini açıkladığı, her iki bağımsız değişkenin de modele katkısının ve öz yeterliğin aracı etkisinin anlamlı olduğu görülmüştür.

Anahtar sözcükler: Sınıf yönetim becerileri, duygusal zekâ, öz yeterlik inancı, aracılık, öğretmen

Atıf:

Sağlam, H. ve Kavgacı, H. (2021). Öğretmenlerin duygusal zekâları ile sınıf yönetim becerileri arasındaki ilişkide öz yeterlik inancının aracılık rolü. Pamukkale Üniversitesi Eğitim Fakültesi Dergisi, 52, 389-416. doi:10.9779.pauefd.775406

\footnotetext{
* Bu makale Dr. Hasan KAVGACI danışmanlığında hazırlanan “Öğretmenlerin Duygusal Zekaları ve Öz Yeterlik İnançları ile Sınıf Yönetimi Becerileri Arasındaki İlişkinin İncelenmesi” isimli tez çalışmasından üretilmiştir. (Tez No: 534921). Çalışmanın bir kısmı ise, 18-22 Nisan 2018 tarihleri arasında 27. Uluslararası Eğitim Bilimleri Kongresi’nde sözlü bildiri olarak sunulmuştur.

** Öğr. Gör., Kastamonu Üniversitesi Cide Rıfat Ilgaz Meslek Yüksekokulu, hdy.sglm@gmail.com ORCID: https://orcid.org/0000-0001-6025-7885

*** Dr., Milli Eğitim Bakanlı̆̆ı Talim ve Terbiye Kurulu Başkanlı̆̆ı, hasank83@gmail.com ORCID: https://orcid.org/0000-0001-5016-7704
} 


\section{GIRIŞ}

Sınıf yönetimi; sınıfta kaynak, insan, öğretim ve zaman yönetimi için uygun ortam sağlama (Çelik, 2013; Erdoğan, 2015); sınıf kurallarını belirleme (Çelik, 2013); öğrencinin, öğretmenin, zamanın, mekânın, motivasyonun, teknolojinin, eğitim programı ve planının, öğretim yönteminin etkinliği gibi sınıftaki unsurların sistemli ve bilinçli biçimde işlerliğini sağlayarak, öğrenci davranışlarını denetleyerek pozitif öğrenme ortamını geliştirme sürecidir (Baloğlu, 2001; Çelik, 2013; Sarıtaş, 2003; Taş, 2015; Yüksel, 2013). Bir başka tanıma göre ise, sınıf yönetimi “sınıftaki öğrencilerin işbirliği içerisinde hareket edebilmesi, belirli hedeflere ulaşabilmeleri yönünde yönetilmesi, bunun için gerçekleştirilen iş ve gayretler toplamı, sınıfta var olan her türlü kaynağı kullanabilme, gelmesi tahmin edilen zorlukları aşabilme" şeklindedir. (Erdoğan, 2015, s. 13). Yapılan tanımlardan yola çıkılarak sınıf yönetimi; eğitim sistemi içerisinde yer alan öğretmenlerin, öğrencilerin tüm ihtiyaçlarını göz önünde bulundurarak çeşitli araç-gereç, yöntem, teknik ve materyalleri etkili bir şekilde kullanma ve öğrencilere rehber olacak şekilde pozitif bir sınıf iklimi oluşturma süreci olarak açıklanabilir.

Pozitif sınıf iklimi oluşturma sürecinde öğretmenlerin; hayatını öğrencileri için vakfetmesi, öğrencilerin hareketlerine yön verebilmesi, teknolojiyi kullanabilmesi ve çocuk gelişimine yönelik mesleki yeterlik sahibi olması ile planlı biçimde eğitim-öğretim uygulama, öğrenme-öğretme ortamında sağlıklı iletişim kurabilme, öğrenci izlemedeğerlendirme yapabilme, okulda çalışan personelle işbirliği yapabilme, gerekli mevzuatlara hâkim olabilme ve mesleki gelişim sağlayabilme gibi niteliklere vakıf olabilmesi gerekmektedir [Türk Eğitim Derneği (TED), 2009]. Ayrıca öğretmenlerin mesleki niteliklerinin içerisinde etkili sınıf yönetimi de bulunmaktadır (Gültekin, 2020). Bu yeterliklere ulaşmak öğretmenlerin eğitme nitelikleri kadar yönetme niteliklerinin de geliştirilmesini gerektirmektedir (Demirtaş, 2015). Çünkü sınıfın iyi yönetilmesi sonucu, öğretim verime ve başarıya ulaşabilir. Dolayısıyla sınıf yönetimi, öğretimin etkili ve başarılı olabilmesinde esas belirleyici olarak görülmektedir (Erdoğan, 2015). Öğretmenlerin etkili ve verimli olabilmesi için öğrenme-öğretme ortamını sağlıklı biçimde planlaması ve yönetmesi gerekmektedir. Öğretmenler bu becerilere sahip olarak öğrencilerin öğrenme ve karar verme süreçlerinde aktif olabilmelerini sağlarlarken aynı zamanda gerek akademik gerekse toplumsal süreçlerde etkin olabilmelerini de amaçlarlar. Öğrencilerin düşünce, görüş ve bilgi donanımları sınıfın demokratik biçimde yönetilmesiyle, sınıf dokusunu güçlendirmektedir (Grant ve Gillette, 2006). TED'in (2009) yaptığı bir araştırmaya göre öğrencilerin 
çoğunluğunun sınıfa severek ve isteyerek geldiklerini vurgulamalarına karşın öğretmenler tarafından öğrencilerin öğrenmeye istekli olmadığı ifade edilmektedir. Öğrencilerin bir kısmının sınıfta rahat hissetmediklerini, öğretmen gözünde kendilerini değersiz hissettiklerini, öğretmenlerin öğrencilerden bekledikleri davranışları kendilerinin yapmadıklarını, adil davranmadıklarını belirtmeleri araştırmanın diğer sonuçlarındandır. $\mathrm{Bu}$ duruma rağmen öğrencilerin sınıfa severek ve isteyerek gelmelerinin sebebinin akran ilişkilerinden kaynaklandığı düşünülmektedir. Öğretmenlerin böyle bir durumda öğrenme öğretme sürecini adil davranımlarıyla, çocuğun yaş, gelişim özellikleri, ilgi ve bireysel farklılıklarını göz önüne alarak öğrencilerde öğrenme isteği geliştirecek biçimde tasarlaması gerekmektedir. Öğrencilerin öğrenme isteklerini geliştirmek bir bakıma öğretmenlerin öğrenci öğrenmesini etkileme, yani uygun yeterliğe sahip olmasını gerektirmektedir (Epstein ve Willhite, 2015). Tartışılan çalışmaların özeti olarak sınıf yönetim becerilerinin öğretmenlerin yansıtıcı görevi görüp hem çocukları hem de kendilerini geliştirerek eğitim, öğretme ve öğrenme alanı olan sınıfa iç hazinesini aktardığı yetkinlikler bütünü olduğu ifade edilebilir. Öğretmenlerin bu alanı en etkili biçimde kullanmaları için öncelikle eğitim alanına sağlıklı biçimde liderlik etmeye, bu sayede sınıf yönetim becerileri kazanmaya ihtiyaçları olduğu söylenebilir.

Öğretmenler, sınıf yönetim becerilerini kullanırken çocukların duygularını dışa vurmalarını sağlama ve paylaşma duygusu kazandırma gibi durumları dikkate almaktadır (Denizel Güven ve Cevher, 2005). Bu kapsamda öğretmenlerin öncelikle kendilerini tanıyabilme, ardından öğrencilere değer verme, saygı gösterme gibi yeterliklere sahip olmaları gerektiği söylenebilir [Milli Eğitim Bakanlığı (MEB), 2017]. Kendini ve çevresindeki insanları tam anlamıyla tanımanın ise bilişsel, sosyal ve duygusal boyutları da kapsadığı ifade edilebilir. Bu bakımdan, kendi duygularını tanımayan veya öğrencilerinin duygularının farkına varmayan bir öğretmenin eksik kaldığı ve sınıf yönetim becerilerinin önemli yeterliklerinden birinin de duygusal zekâ olduğu düşünülmektedir. Koçoğlu'na (2011) göre de yeterliği kuvvetli olan bireylerin duygusal zekâlarının da kuvvetli olduğu bilindiğinden sınıf yönetimi ve duygusal zekâ arasındaki ilişkinin incelenmesi olağandır.

Duygusal zekâ "duyguları tanımak ve yönetmek, karşıdaki kişi ya da kişilerin duygularını fark etmek, sosyal ilişkileri yönetebilmek" becerilerini içermektedir (Tuyan ve Beceren, 2004, s. 38). Yapılan bazı araştırmalar sonucunda; duygusal zekânın bireyin duygularını tanıma, bu duyguları yönetme, kendisini motive etme, başkalarının duygularını tanıma ve başarılı ilişkiler geliştirme becerileri şeklinde beş kritik bileşeni olduğu ifade 
edilmektedir (Goleman, Bennet ve Barlow, 2012). Bu yönler ele alındığında Salovey ve Mayer (1990, s.189) duygusal zekâyı "bireyin duygu aktarabilmeyi, ayırt edebilmeyi, bilgilerini kullanabilmeyi içeren sosyal zekâ türü"; Goleman (2010, s.62) ise; "kendini harekete geçirebilme, sorunlara rağmen hayatını sürdürebilme, ruh halini düzenleyebilme" şeklinde tanımlamıştır. Bununla birlikte duygusal zekâ, problemleri gerçekçi ve esnek bir şekilde çözerek hem bireysel faktörlerle hem de çevreyle baş edebilmeyi (Bar-On, 2006), bireyin kendinin ve başkalarının duygularını anlamayı, olayları anlamlandırmayı (Geçikli, 2013, s. 306), benzer şekilde duygusal bilgiyi anlayıp bunların bir yansıması olarak duygusal-zihni gelişimi (Akgemci ve Doğanalp, 2008) ve tüm bunları yönetebilmeyi (Robbins ve Judge, 2015) içermektedir. Duygusal zekâsı yüksek insanlar iletişim, empati, kontrol, uyum, işbirliği, motivasyon, başkalarını etkileme, liderlik gibi özelliklerini çevrelerine yansıtmaktadır (Tunca, 2010). Ayrıca algılama, anlama, ifade etme, sınıflandırma, yönetme ve düzenleme yeteneğinin yani duygusal zekânın öğretmen verimliliği üzerinde olumlu etkileri olduğu ortaya koyulmuştur (Valente, Veiga-Branco, Rebelo, Lourenço ve Cristóvão, 2020). Bu nedenle, öğretmenlerin sinıf ortamında göstermesi gereken yönetim becerilerinin duygusal zekâyı oluşturan öğelerle örtüştüğü söylenebilir. Bu bağlamda son zamanlarda önemi anlaşılan duygusal zekâ, sınıf yönetimi ile ilişkisi araştırılan önemli bir değişkendir (Denizel Güven ve Cevher, 2005; Karagözoğlu, 2016; Köprülü, Turhan ve Helvacı, 2018; Özdevecioğlu, Akın, Karaca ve İştahlı, 2014; Tok, Tok ve Doğan Dolapçioğlu, 2013; Toytok, 2013; Tunca, 2010). Öğretmenin hem kendisinin hem de öğrencilerin ruh hallerini ve duygularını anlama ve yönetme becerisi düşünüldüğünde, duygusal zekânın liderliğe katkıda bulunduğu söylenebilir. Bu kapsamda George (2000) da duygusal zekânın organizasyonlarda etkili liderliğe katkıda bulunduğunu öne sürmektedir. Rosete ve Ciarrochi (2005) ise daha yüksek duygusal zekânın daha yüksek liderlik etkinliği ile ilişskili olduğunu açıklamaktadır. Bütün bu araştırmalar birlikte değerlendirildiğinde öğretmenlerin sınıf yönetim becerileri ile duygusal zekâları arasında pozitif yönde anlamlı bir ilişkinin varlığı beklenmektedir.

Yukarıdaki tartışmalarda da dile getirildiği gibi sınıf yönetim becerileri öğrenmeöğretme süreçlerini temel almaktadır. Öğrenme-öğretme sürecinde, öğretmenin rol aldığ beceriler, öğretmen yeterlikleri olarak belirtilmiştir (MEB, 2017). Ross'un (1992) araştırmasında kişisel yeterliliğe sahip olan öğretmenlerin sınıflarındaki öğrenci başarısının daha fazla olduğu sonucuna ulaşılmıştır. Öğretmenlerin kendilerine olan güveni artırdığında daha etkili eğitim olanağ1 sundukları düşünüldüğünde öğretme sürecinde öğretmen için 
gerekli olan yeterliklerden birinin de öz yeterlik olduğu söylenebilir. Woolfolk Hoy ve Spero (2005), öğretmen yeterliği ile öz yeterlik arasında orta düzey ilişki olduğunu bulmuştur. Sosyal bilimlerde ve özellikle de psikolojideki araştırmalarda pozitif psikoloji akımı ile (Luthans, 2002) daha da çok gündeme gelen öz yeterlik algısı, Bandura'ya (1982) göre bireylerin karşılaştıkları durumlarla baş edebilmek amacıyla yapılacak davranışları ne kadar iyi yapabileceğine dair inancı olarak tanımlanmaktadır. Batar ve Aydın’a (2014) göre bireyin öz yeterliğinin gelişeceğine dair kesin düşüncesi ancak bireyi ilgilendiren ve keşfe açık beceri sürecidir. Bu bağlamda, öğretmen öz yeterliği ise öğretmenin öğretme işini yerine getirebilmek için gereken faaliyetleri düzenleme becerisine ilişkin algılarıdır (Tschannen-Moran, Woolfolk Hoy ve Hoy, 1998). Bununla birlikte öz yeterliği Senemoğlu (2013), bireylerin karşılaşacağı zorlukları aşmada kendinde gördüğü başarıya ilişkin inancı; Korkmaz (2013), bireylerin yaptığı davranış ile yapması gereken davranışın ne kadar örtüştüğünü fark edebilmesi; Aksoy (2011), bireylerin bir görevi yapabileceğine ilişkin inanc1; Hoy ve Miskel (2012) ise bireylerin bir işi yapabileceğine ilişkin kendini değerlendirmesi olarak tanımlamaktadır. İlgili alan yazında bireylerin öz yeterliklerini kullanarak sınıf yönetim becerilerini geliştirebileceklerini destekler nitelikte her iki değişken arasındaki ilişkiyi ortaya koyan çalışmalar bulunmaktadır (Abu Tineh, Khasawneh ve Khalaileh, 2011; Babaoğlan ve Korkut, 2010; Demir, 2015; Güneş, 2016; İpek ve İpek, 2015; Özbezek ve Paksoy, 2017).

Alan yazındaki öz yeterlilik-duygusal zekâ arasındaki ilişkiye bakıldığında, bireyin duygu ve düşüncelerinin, kendisiyle ilgili algılarını ve öz yeterlik inancını güçlendirdiği söylenebilir. Eğitimciler üzerinde yapılan araştırmalarda öğretmenlerin ve üniversite öğretim elemanlarının öz yeterlilikleriyle, duygusal zekâ ve öğretmen yetkinliği arasında pozitif ilişkiler bulunduğu görülmektedir (Abdolvahabi, Bagheri, Haghighi ve Karimi, 2012; Amirian ve Behshad, 2016; Çelik Ağırman ve Naktiyok, 2018; Di Fabio ve Palazzeschi, 2008; Hashemi ve Ghanizadeh, 2011; Karamehmetoğlu, 2017; Ramchunder ve Martins, 2014; Rastegar ve Memarpour, 2009; Öcal ve Şenel, 2016; Özbezek ve Paksoy, 2017; Sert ve Traş, 2019; Sarkhosh ve Rezaee, 2014; Şenel, 2015; Şenel, Adiloğulları ve Ulucan, 2014; Wu, Lian, Hong, Liu, Lin ve Lian, 2019). Bu bulgu öğretmenlerin duygusal zekâlarının gelişimi ve öz yeterlilik inançlarını etkili kullanmaları sonucunda özellikle de sınıf yönetimindeki yetkinlik bağlamında başarıya ulaşılabileceği düşüncesini desteklemektedir. Diğer bir araştırmanın sonucuna göre ise duygusal zekâ ve öğretmen öz yeterliği arasında hem küresel hem de üç boyutta (öğretim stratejisinde etkinlik, sınıf yönetiminde etkinlik ve 
öğrenci katılımındaki etkinlik) bir takım önemli ve pozitif ilişkiler bulunmaktadır (Di Fabio ve Palazzeschi, 2008). Bu durumda duygusal zekâ ve öz yeterlik inancının öğretmenlerin sınıf yönetim becerilerini de etkileyeceği düşünülmektedir.

Sonuç olarak, bireylerin duygu, düşünce ve davranışları birbirinden farklı olduğu için yaşanılan olaylara bakış açıları da farklı olmaktadır. Oluşan bu farklılıklar zaman zaman, bireyler arası anlaşmazlık ve huzursuzluğu da beraberinde getirebilmektedir. Anlaşmazlık ve huzursuzlukları çözmek ve oluşan farklı durumları yönetmek duygusal zekâya sahip olmayı gerektirir. Bu durum da bireyin kendisini geliştirmesiyle sağlanabilir (Geçikli, 2013). Öğretmen, öğrenme öğretme sürecinde öğrencilerden gelebilecek geri bildirimleri önemseyerek öğrencilerde yaratıcı düşünce tarzının gelişmesini, sorumluluk sahibi bireyler olarak davranmasını sağlayarak, istenmeyen davranışların ortadan kaldırılması için öncelikle öğrencileri anlamalı ve bu duruma göre sınıf ortamını yeniden yapılandırmalıdır. Dolayısıyla öğretmenler iyimser bir bakış açısıyla, kendisinin ve çocukların duygularını, düşüncelerini de dikkate alarak hareket etmek ve sınıfı bu becerilerle yönetmek zorundadır. Bu beceriler, duygusal zekâyı oluşturan etmenlerle de büyük ölçüde benzerlik göstermektedir (Tunca, 2010). Bununla birlikte öğretmenler problem çözebilen, araştıran, eleştiren, bilgiye erişebilen, kendine güven duyan insanlar yetiştirebilmelidir. Tüm bu faktörler öğretmenlerin öz yeterlik inançlarının farkında olmalarına da bağlıdır (Eker, 2014). Bu nedenle iyi yetişmiş öğretmenlerin öncelikle öz-yeterlik inancının da gelişmiş olması gerekmektedir (Üredi ve Üredi, 2006).

Sınıf yönetim becerilerini etkili bir biçimde kullanan öğretmenler sınıfta olumlu bir hava oluşmasını sağlayacaktır. Öğretmen, zamanını verimli kullanarak çocukların stresten uzak, paylaşımcı, etkin ve hoşgörülü bir sınıf ortamında eğitim almalarına yardımcı olacaktır. Bununla birlikte Karamehmetoğlu'na (2017) göre duygusal zekânın da gelişmesiyle öğretmenler, derslere öğrenci katılımını yükseltmekte, öğretim stratejilerini çeşitlendirebilmekte, daha verimli sınıf yönetimi sağlamakta ve mesleki anlamda özyeterlik algıları kuvvetlenmektedir. Bu durum sınıf yönetimi için önemli bir kolaylıktır. Tüm bu özellikler, duygusal zekânın da boyutlarını oluşturduğu için öğretmenlerin duygusal zekâları sınıf yönetim becerilerinin de gelişmesine yardımcı olacaktır. Hem sınıf yönetimi hem de duygusal zekâlarının kullanımında kendisini yeterli hissetmeyen öğretmenlerde güvensizlik oluşacağı ve bu güvensizliğin öğrenme ortamını olumsuz etkileyeceği ifade edilebilir.

Özetle sınıf yönetim becerilerinin, duygusal zekâ kullanımının ve öz yeterlik inancının birbiriyle ilişkili ve aynı zamanda öğretmenlerin sınıf yönetim becerilerinin, duygusal 
zekâlarının ve öz yeterlik inançlarının eğitsel amaçlara ulaşmada önemli faktörler olduğu düşünülmektedir. $\mathrm{Bu}$ bağlamda ilgili alan yazın öğretmenlerin sınıf yönetim becerileri, duygusal zekâları ve öz yeterlilik inançları değişkenleri arasında bir ilişki olabileceği varsayımını desteklemektedir. Fakat yapılan çalışmaların genellikle bu değişkenler arasındaki ikili ilişkileri incelediği görülmüş ve sınıf yönetim becerilerinin açıklanmasında duygusal zekâ ve öz yeterlilik inancı gibi bireysel değişkenlerin rolünü inceleyen çalışmalara rastlanılmamıştır. Dolayısıyla sınıf yönetim becerisi, duygusal zekâ ve öz yeterlik inancının birbirine paralel olduğunu gören öğretmenlerin; kendi yeterliklerinin farkına varabilmesi adına gayret göstermesi ve daha verimli eğitim-öğretim süreci içerisine girebilmek bakımından sadece plan-program etkinlikleri, fiziksel düzen, öğretmen-öğrenci ilişkilerinin düzenlenmesi, zaman kullanımı, sınıf içi etkileşim ve davranış düzenlemelerine değil aynı zamanda iletişim, empati, kontrol, uyum, işbirliği, motivasyon, başkalarını etkileme gibi duygusal anlamda ve özellikle eğitim-öğretim sürecinde başarıya ulaşabileceğine olan inancını artırmaya yönelik girişimlerde bulunmalarına katkı sağlayacağı düşünülmektedir.

\section{Araştırmanın Amacı}

$\mathrm{Bu}$ araştırmanın temel amacını okul öncesi ve ilköğretim öğretmenlerinin duygusal zekâları ve sınıf yönetim becerileri arasındaki ilişkilerin ve bu ilişkide öz yeterlik inancının aracılık rolünün incelenmesi oluşturmaktadır. Bu bağlamda araştırma kapsamında aşağıda belirtilen alt problemlerin cevabı aranacaktır:

1. Öğretmenlerin duygusal zekâları, öz yeterlik inançları ve sınıf yönetim becerileri ile alt boyutları arasında anlamlı ilișkiler var mıdır?

2. Öğretmenlerin duygusal zekâları ile öz yeterlik inançları sınıf yönetim becerileri ve alt boyutlarının anlamlı yordayıcısı midir?

3. Öğretmenlerin duygusal zekâları ile sınıf yönetim becerileri ve alt boyutları arasında öz yeterlik inancının aracılık rolü anlamlı mıdır?

\section{Yöntem}

\section{Araştırmanın Modeli}

$\mathrm{Bu}$ araştırma, öğretmenlerin duygusal zekâları, öz yeterlik inançları ve sınıf yönetim becerileri arasındaki ilişkilerin incelendiği ilişkisel tarama modelinde tasarlanmış nicel bir 
çalışmadır. Araştırmada duygusal zekâ bağımsız değişken, sınıf yönetimi bağımlı değişken, öz yeterlik inancı ise aracı değişkendir.

\section{Çalışma Grubu}

Araştırmanın çalışma grubunu 2017-2018 eğitim-öğretim yılında Kastamonu il ve ilçelerinde Milli Eğitim Bakanlığı'na bağlı devlet okullarında görevli ve yaş ortalaması 37 olan $(S D=8.7) 376$ okulöncesi ve ilköğretim öğretmeni oluşturmuştur. Çalışma grubunun \% 68'i (n= 254) kadın, \% 32'si $(n=122)$ erkek; \% 26'sı $(n=99) 22$ - 30 yaş, \% 44'ü $(n=$ 165) 31-40 yaş, \% 30’u $(n=112) 41$ ve üzeri yaş grubundan; \% 14'ü $(n=54)$ okul öncesi, \% 32'si (n=121) sinıf, \% 54'ü $(\mathrm{n}=201)$ branş öğretmeninden; \% 44'ü $(\mathrm{n}=166)$ 1-10 yı1, \% 35'i $(\mathrm{n}=130)$ 11-20 yıl \% 21'i $(\mathrm{n}=80) 21$ yıl ve üzeri kıdemden; \% 5'i $(\mathrm{n}=18)$ yüksekokul, \% 89’u $(n=336)$ lisans, ve \% 6’sı $(n=22)$ yüksek lisans mezunundan oluşmaktadır.

\section{Veri Toplama Araçları}

Araştırmanın verileri 3 farklı ölçek aracılığıyla toplanmıştır. Ayrıca veri toplama formuna, katılımcılarla ilgili demografik bilgiler toplanması için kısa bir bölüm eklenmiştir.

\section{Duygusal Zekâ Özelliği Ölçĕgi-Kısa Form}

Petrides ve Furnham (2001) tarafından geliştirilmiş ve 20 maddeden oluşan 7'li Likert tipi Duygusal Zekâ Özelliği Ölçeği-Kısa Formu'nun (DZÖÖ-KF) Türkçe versiyonunun geçerlik-güvenirlik analizleri üniversite öğrencileri ile Deniz, Özer ve Işık (2013) tarafından gerçekleştirilmiştir. Mevcut araştırmada geçerlik-güvenirlik analizleri yeniden yapıldığında AFA sonucunda tüm maddelerin toplam varyansının \% 31'ini açıkladığı görülmektedir (özdeğer = 5.986). Madde analizine göre 15. maddenin faktör yükü .30'dan küçük olduğundan ölçekten çıkarılmıştır. Ayrıca maddelerin faktör yükleri .34 - .70 arasındadır. Ölçeğin ilk faktörünün toplam varyansın \% 30'undan fazlasını açıkladığından toplam puan kullanılmıştır. Ölçeğin Cronbach's Alpha iç tutarlık katsayısı .87, düzeltilmiş madde toplam korelasyonları $.35-.65$ arasındadır.

\section{Ögretmen Öz Yeterlik İnancı Ölçĕgi}

Tschannen-Moran ve Hoy (2001) tarafından geliştirilmiş ve Çapa, Çakıroğlu ve Sarıkaya (2005) tarafından Türkçeye uyarlanmış, kısa forma ilişkin geçerlik güvenirlik analizi Kavgacı (2014) tarafından yapılmıştır. Öğretmen Öz Yeterlik Ölçeği (Kısa Form); 9'lu Likert tipi toplam 12 maddeden oluşmuştur. İkinci düzey faktör analizi sonuçlarına göre 
ölçek maddelerinin tek boyut etrafında toplandığı ifade edilmiştir. Mevcut araştırmada tekrarlanan geçerlik-güvenirlik analizlerine göre ölçeğin temel bileşenler analizi maddelerin tek boyut altında toplandığını ve toplam varyansın \% 54'ünü açıkladığını göstermiştir (özdeğer = 6.456). Ölçek maddelerinin faktör yükleri .67 - .79; Cronbach's Alpha iç tutarlık katsayıs1 .92; madde toplam korelasyon katsayıları ise .61 - .73 arasındadır.

\section{Sinıf Yönetim Becerileri Ölçeği}

Delson (1982) tarafından geliştirilmiş ve Yalçınkaya ve Tonbul (2002) tarafından Türkçeye uyarlanan ölçek 5'li Likert tipi toplam 25 maddeden oluşmaktadır. Korkut (2009) tarafindan Türkçeye uyarlama çalışmasında ölçeğin yeniden analizi yapılarak madde sayısı 15'e indirilmiş ve ölçek; "Fiziksel Düzen Plan Program Etkinlikleri”, “Öğretmen-Öğrenci İlişkilerinin Düzenlenmesi” ve "Zaman Kullanımı ile Sınıf İçi Etkileşim ve Davranış Düzenlemeleri” olarak üç alt faktörden oluşmuştur. Mevcut araştırmada geçerlik-güvenirlik çalışmaları tekrarlanmıştır. Bileşen matrisi incelendiğinde 6. ve 10. maddeler binişiklik problemi nedeniyle ölçekten çıkartılmıştır. Böylelikle ölçekte başlangıçta 15 olan madde sayısı güvenirlik analizi sonucunda 13'e düşmüştür. 13 madde üzerinden yapılan faktör analizinde Korkut (2009) tarafından ele alınan ikinci ve üçüncü boyutların tek boyut etrafında toplandığı görülmüştür. Bu çalışmaya göre birinci boyut “İlişki ve Davranış Düzenlemesi" (açıklanan varyans = \% 26; Öz-değer = 3,405), ikinci boyut "Fiziksel Düzen ve Plan Program Etkinlikleri” (açıklanan varyans = \% 24; öz-değer = 3,118) olarak adlandırılmıştır. Alt boyutlardaki maddelerin düzeltilmiş madde toplam korelasyon katsayıları .46 - .61; madde faktör yükleri .50 - .75 arasındadır. İki boyut toplam varyansın \% 50'sini açıklamaktadır. Cronbach's Alpha iç tutarlık katsayıları; “İlişki ve Davranış Düzenlemesi" alt boyutu için .82, "Fiziksel Düzen ve Plan Program Etkinlikleri” alt boyutu için .79; tüm ölçek için .86' dır.

\section{Veri Analizi}

Araştırmada SPSS-21 paket programı kullanılarak betimleyici istatistikler yapılmıştır. Buna göre araştırma değişkenlerinin basıklık ve çarpıklık değerlerinin -.17 ile .77 arasında değiştiği görülmüştür. Değişkenler arasındaki ilişki incelemesinde Pearson Momentler Çarpım Korelasyon Katsayısı hesaplanmıştır. Bağımsız değişkenlerin bağımlı değişkenleri yordama düzeylerini belirlemek için Çoklu Regresyon Analizi yapılmıştır. Son olarak, öğretmen öz yeterliğinin duygusal zekâ ile sınıf yönetimi arasındaki aracılık rolünü analiz etmek için Hayes (2013) tarafından SPSS için geliştirilen bootstrap örneklemesine dayanan PROCESS isimli makro kullanılmıştır. Güven aralıkları 5000 yeniden örnekleme üzerinden 
hesaplanmıştır. Aracı etkinin anlamlılığının hesaplanmasına yönelik tartışmalarda Sobel $z$ testi gibi sık kullanılan yöntemlerin normal dağılım varsayımına dayandığı ifade edilmektedir. Ancak Baron ve Kenny (1986) modelinde açıklanan aracı etki (paths a.b) normal dağılıma sahip olmadığından Sobel $z$ testinin doğru sonuçlar çıkarmayacağı belirtilmektedir. $\mathrm{Bu}$ çerçevede aracı etki ve standart hata hesaplanması için bootstrap yönteminin kullanımı yaygınlaşmaya başlanmıştır (Hayes, 2009; MacKinnon, Lockwood ve Williams, 2004). Mevcut araştırmada gerek ulusal (Kavgacı ve Çalık, 2017) gerekse uluslararası yayınlarda (Loflin ve Barry, 2016; Schwarzer, Antoniuk ve Gholami, 2015) görülmeye başlanan bootstrap yöntemini uygulayan PROCESS makrosu tercih edilmiştir.

\section{Bulgular}

Bu bölümde ilk olarak öğretmenlerin duygusal zekâları, öz yeterlikleri ve sınıf yönetim becerileri arasındaki ilişkilere yönelik Pearson Momentler Çarpımı Korelasyon Katsayıları hesaplanmış ve Tablo 1'de sunulmuştur.

Tablo 1. Değişkenler Arası İlişkilere Yönelik Bulgular

\begin{tabular}{lccccc}
\hline Değişkenler & 1 & 2 & 3 & 4 & 5 \\
\hline 1. Sınıf Yönetim Becerileri & - & $.89^{* * *}$ & $.89^{* * *}$ & $.38^{* * *}$ & $.69^{* * *}$ \\
2. İlişki ve Davranış Düzenlemesi & - & $.58^{* * *}$ & $.41^{* * *}$ & $.59^{* * * *}$ \\
3. Fiziksel Düzen ve Plan Program Etkinlikleri & & - & $.26 * * *$ & $.64 * * *$ \\
4. Duygusal Zekâ Özelliği & & & - & $.44^{* * *}$ \\
5. Öğretmen Öz yeterliği & & & & - \\
\hline
\end{tabular}

$* * * p<.001$

Tablo 1'e bakıldığında öz yeterlik ve duygusal zekânın sınıf yönetim becerileri ile orta derecede anlamlı ilişkisine rağmen öz yeterliğin duygusal zekâya oranla sınıf yönetim becerileri ile ilişkisi daha güçlü görülmektedir. Ayrıca "İlişski ve Davranış Düzenlemesi” boyutunun bağımsız değişkenlerle ilişkisinin "Fiziksel Düzen ve Plan Program Etkinlikleri” boyutuna göre daha güçlü olduğu saptanmıştır.

Araştırmada duygusal zekâ ve öz yeterliğin sınıf yönetim becerilerini yordama durumu doğrusal Çoklu Regresyon Analizi ile saptanmıştır. Bulgular Tablo 2'de sunulmuştur. Tablodan da görüleceği üzere duygusal zekâ tek başına sınıf yönetim becerilerinin "Fiziksel Düzen ve Plan Program Etkinlikleri” boyutunun \% 7'sini; ikinci 
adımda eklenen öz yeterlikse "Fiziksel Düzen ve Plan Program Etkinlikleri” boyutunun \% 34'ünü açıklamaktadır. Her ikisi birlikte "Fiziksel Düzen ve Plan Program Etkinlikleri" boyutundaki değişimin \% 41'ini yordamaktadır. İki değişkenin birlikte ele alınıp "Fiziksel Düzen ve Plan Program Etkinlikleri” alt boyutuna katkıları incelendiğinde birinci adımdaki katkısı anlamlı olan duygusal zekânın öz yeterliğin eklenmesiyle anlamsızlaştığı görülmektedir $(\beta=-.03, p>.05)$. Öz yeterliğin ise "Fiziksel Düzen ve Plan Program Etkinlikleri” alt boyutuna katkısı anlamlıdır $(\beta=.65, p<.05)$. Bu durum öz yeterliğin duygusal zekâ ile "Fiziksel Düzen ve Plan Program Etkinlikleri” boyutu arasındaki ilişkide tam aracılık etkisinin olabileceğine, bir başka deyişle duygusal zekânın sınıf yönetim becerilerinin "Fiziksel Düzen ve Plan Program Etkinlikleri” boyutunu öz yeterlik üzerinden dolaylı olarak etkileyebileceğine işaret etmektedir.

Tablo 2. Duygusal Zekâ ve Öz Yeterliğin Sinıf Yönetim Becerileri ve Alt Boyutlarını Yordamasına Yönelik Bulgular

\begin{tabular}{|c|c|c|c|c|c|c|c|c|c|}
\hline \multirow[b]{2}{*}{ Değişkenler } & \multicolumn{3}{|c|}{$\begin{array}{c}\text { Fiziksel Düzen ve Plan } \\
\text { Program Etkinlikleri }\end{array}$} & \multicolumn{3}{|c|}{$\begin{array}{l}\text { İlişki ve Davranış } \\
\text { Düzenlemesi }\end{array}$} & \multicolumn{3}{|c|}{$\begin{array}{l}\text { Sınıf Yönetim } \\
\text { Becerileri } \\
\text { (Toplam Puan) }\end{array}$} \\
\hline & $\beta$ & $\bar{t}$ & $p$ & $\bar{\beta}$ & $\bar{t}$ & $p$ & $\beta$ & $\bar{t}$ & $\bar{p}$ \\
\hline \multicolumn{10}{|l|}{ 1. Adım } \\
\hline $\begin{array}{c}\text { Duygusal } \\
\text { zekâ }\end{array}$ & .26 & 5.25 & .000 & .41 & 8.748 & .000 & .38 & 7.92 & .000 \\
\hline$R^{2}$ & & .07 & & & .17 & & & .14 & \\
\hline$F$ & & 27.542 & .000 & & 76.523 & .000 & & 62.688 & .000 \\
\hline \multicolumn{10}{|l|}{ 2. Adım } \\
\hline $\begin{array}{c}\text { Duygusal } \\
\text { zekâ }\end{array}$ & -.03 & -.60 & .552 & .19 & 4.073 & .000 & .09 & 2.15 & .032 \\
\hline Öz yeterlik & .65 & 14.572 & .000 & .51 & 11.177 & .000 & .65 & 15.71 & .000 \\
\hline$R^{2}$ toplam & & .41 & & & .38 & & & .48 & \\
\hline$\Delta R^{2}$ & & .34 & & & .21 & & & .34 & \\
\hline$F$ & & 127.721 & .000 & & 113.400 & .000 & & 175.398 & .000 \\
\hline$\Delta F$ & & 212.336 & .000 & & 124.922 & .000 & & 246.893 & .000 \\
\hline
\end{tabular}


“İlişki ve Davranış Düzenlemesi” boyutunun yordanmasına yönelik bulgular için duygusal zekânın değişimin \% 17'sini, öz yeterliğin ise duygusal zekâ kontrol edildiğinde gerçekleşen değişimin \% 21'ini yordadığı görülmektedir. Duygusal zekâ ve öz yeterlik “İlişki ve Davranış Düzenlemesi” boyutundaki değişimin \% 38'ini açıklamaktadır. İki değişkenin birlikte ele alındığı "İlişki ve Davranış Düzenlemesi” alt boyutunda öz yeterliğin $(\beta=.51, p<.05)$ duygusal zekâya $(\beta=.19, p<.05)$ göre daha güçlü bir yordayıcı olduğu görülmektedir.

Sınıf yönetim becerilerine ilişkin toplam puanın yordanmasına yönelik bulgulara bakıldığında duygusal zekânın sınıf yönetim becerilerinde gerçekleşen değişimin \% 14'ünü, öz yeterliğin ise duygusal zekâ kontrol edildiğinde \% 34'ünü yordadığı görülmektedir. Modele eklenen bağımsız değişkenler, birlikte sınıf yönetim becerilerindeki değişimin \% 48'ini yordamaktadır. İki değişkenin modele birlikte katkıları incelendiğinde öz yeterliğin ( $\beta$ $=.65, p<.05)$ duygusal zekâya $(\beta=.09, p<.05)$ göre daha güçlü yordayıcı olduğu görülmektedir. Bulgularda dikkat çeken nokta duygusal zekânın sınıf yönetim becerileriyle ilişkilerini gösteren standartlaştırılmış regresyon katsayılarında öz yeterliğin modele eklenmesiyle \% 50'den fazla bir düşüş yaşanmasıdır. Bununla birlikte, her iki adımda da duygusal zekânın modele katkısı anlamlıdır $(p<.05)$. Bu durum öz yeterliğin duygusal zekâ ile sınıf yönetim becerileri arasındaki ilişkide kısmi bir aracı etkisinin olabileceğini göstermektedir (Hayes, 2013).

Araştırma bulgularının aracı etkiye işaret etmesi üzerine bu aracı etkinin anlamlılığının incelenmesi gerektiği kararlaştırılmıştır. Bu bağlamda Hayes tarafından SPSS-PROCESS isimli makro (Hayes, 2013) kullanılarak aracılığın anlamlılığı test edilmiştir. Araştırmada sınıf yönetim becerileri, alt boyutlarıyla birlikte, bağımlı değişken olarak kabul edildiği için aracılık analizi üçü için de tekrarlanmış ve bulgular Tablo 3'te verilmiştir.

Tablo 3. Öz Yeterliğin Aracılık Etkisine Yönelik Bulgular

\begin{tabular}{lccccccccc}
\hline & $\begin{array}{c}\text { Fiziksel Düzen ve Plan } \\
\text { Program Etkinlikleri }\end{array}$ & \multicolumn{2}{c}{$\begin{array}{c}\text { İlişki ve Davranış } \\
\text { Düzenlemesi }\end{array}$} & \multicolumn{2}{c}{$\begin{array}{c}\text { Sinıf Yönetim Becerileri } \\
\text { (Toplam Puan) }\end{array}$} \\
\hline $\begin{array}{l}\text { Aracı } \\
\text { Değişken }\end{array}$ & $\beta$ Effect & SE & $\begin{array}{c}\text { LLCI- } \\
\text { ULCI }\end{array}$ & $\beta$ Effect & SE & $\begin{array}{c}\text { LLCI- } \\
\text { ULCI }\end{array}$ & $\beta$ Effect & SE & $\begin{array}{r}\text { LLCI- } \\
\text { ULCI }\end{array}$ \\
\hline $\begin{array}{l}\text { Öz } \\
\text { yeterlik }\end{array}$ & .29 & .03 & $.22-.36$ & .23 & .03 & $.17-.28$ & .29 & .03 & $.23-.35$ \\
\hline
\end{tabular}


Tablo 3'te de belirtildiği üzere duygusal zekânın sınıf yönetimi üzerindeki dolaylı etkisi anlamlıdır (.29; $\mathrm{SE}=.03 ; \mathrm{CI}=[.23, .35] ; p<.01)$. Benzer şekilde, sınıf yönetiminin alt boyutlarından "Fiziksel Düzen ve Plan Program Etkinlikleri" $(.29 ; \mathrm{SE}=.03 ; \mathrm{CI}=[.22$, $.36] ; p<.01)$ ile "İlişki ve Davranış Düzenlemesi”"nde (.23; SE = .03; CI = [.17, .28]; $p<$ .01) de dolaylı etkiler anlamlıdır. Bu doğrultuda, öz yeterliğin "Fiziksel Düzen ve Plan Program Etkinlikleri” alt boyutu ile duygusal zekâ arasındaki ilişkide tam aracılık, diğer modellerde ise anlamlı düzeyde kısmi aracılık rolü üstlendiği ortaya çıkmaktadır. Dolayısıyla regresyon analizinde ortaya çıkan aracılık durumunun doğrulandığ ifade edilebilir. $\mathrm{Bu}$ açıdan, öğretmenlerin duygusal zekâlarının, sınıf yönetim becerilerinin “Fiziksel Düzen ve Plan Program Etkinlikleri” alt boyutu haricinde gerek doğrudan, gerekse öğretmenlik mesleği içinde öz yeterlik algılarını güçlendirerek dolaylı olarak pozitif ve anlamlı düzeyde etkilediği görülmektedir.

\section{Tartışma, Sonuç ve Öneriler}

Araştırmanın bu bölümünde alt amaçlara ilişkin araştırma bulguları alan yazın bağlamında sırasıyla tartışılmıştır. İlk olarak araştırmanın değişkenleri arasındaki anlamlı ilişkilerin incelenmesine yönelik analizler bağımsız değişkenlerin sınıf yönetim becerileriyle anlamlı düzeyde ilişkili olduğunu göstermiştir. Sınıf yönetim becerilerinin alt boyutlarıyla diğer değişkenlerin ilişkilerine bakıldığında en yüksek ilişkiyi öz yeterlik değişkeninin oluşturduğu görülmüştür. Ayrıca sınıf öğretmenlerinin öz yeterlik inançlarıyla sınıf yönetim becerilerinin "Fiziksel Düzen ve Plan-Program Etkinlikleri” ile "İlişki ve Davranış Düzenlemesi” boyutları arasında orta düzeyde pozitif anlamlı ilişki saptanmıştır. Bununla birlikte, "Fiziksel Düzen ve Plan Program Etkinlikleri” boyutunun "İlişki ve Davranış Düzenlemesi” boyutuna göre öz yeterlik ile daha yüksek düzeyde ilişki olduğu görülmektedir. Benzer şekilde, Babaoğlan ve Korkut (2010) ve Korkut'un (2009) çalışmalarında da sınıf yönetim becerileri alt boyutlarının öz yeterlikle anlamlı düzeyde ilişkili olduğu ortaya konmuştur.

Mevcut çalışmada sınıf yönetim becerileriyle en yüksek ilişkinin öz yeterlik ile olduğu görülmüştür. Bu ilişkiye göre öz yeterlik arttıkça sınıf yönetim becerileri; sınıf yönetim becerileri arttıkça da öz yeterlik inancı artmaktadır. Öz yeterliğin içeriğinde öğretmenlerin sınıf yönetim sistemlerini etkili kullanabilmesi, öğrenci seviyesine uygun ders anlatabilmesi, öğrenci değerlendirme yeterliliğinin olması gibi faktörler etkili olduğundan 
sınıf yönetim becerileriyle ilişkisinin anlamlı olması kuramsal olarak da olağan görülmektedir. Sınıf yönetim becerilerinin öğretmen-öğrenci ilişkisi, davranış düzenlemeleri, zaman yönetimi, sınıfın fiziksel düzeni ve plan program etkinlikleri boyutları öğretmenin kendine güveninin artarak bilgilerin öğrencilere daha sağl1klı aktarımına ve kendisine olan inancının artmasına sebep olmaktadır (Başar, 2014). Bu durum da iki değişken arasındaki anlamlı ilişkileri açıklamaktadır. Yapılan araştırmalar incelendiğinde bu sonucun alan yazında yer alan diğer çalışmalar tarafından desteklendiği görülmüştür. Bay (2020), Özçelik (2019), Semerci ve Uyanık Balat (2018) ve Bozbaş (2015)'ın çalışmalarına göre sınıf yönetim becerileri ve öz yeterlik inançları arasında anlamlı ilişki saptanmıştır. Benzer şekilde, Çelik (2019) sınıf yönetim düzeyleri ile öz yeterlik düzeyleri arasında anlamlı bir ilişki saptamıştır. Özbezek ve Paksoy (2017) ise öğrencilerin liderlik etme motivasyonu ile öz yeterlikleri arasında anlamlı ilişki bulmuştur. Güneş’e (2016) göre de öğretmenin sahip olduğu öz yeterlik öğretim içerisindeki liderliğinin önemli bir işaretidir. Bu sonuçlara paralel olarak Porter (2011), öz-yeterliği yüksek olanların liderlik rollerini üstlenmeyi sevdikleri için liderlik etmeye daha yatkın olduklarını belirtmektedir. Kendini yeterli hisseden öğretmenin sınıf içerisindeki performansı artacağından ve bu durumun, sınıfta yaşanabilecek olumsuz faktörlerin azalmasına katkısı olacağından öğretmenlerin öz yeterlikleri etkili bir öğretim yapabilmeleri için önemli bir faktördür. Dolayısıyla öğretmenlerin öz yeterliğinin artması onların sınıf yönetim becerileri noktasında daha başarılı olmalarına katkı sağlayabilmektedir.

Araştırmanın bulgularına göre sınıf yönetim becerilerine katkı sağlayan diğer değişken pozitif yönde anlamlı bir ilişkiye sahip olan duygusal zekâdır. Alan yazın çalışmaları incelendiğinde sınıf yönetim modellerinin alt boyutları ile duygusal zekâ arasında anlamlı ilişki bulunmuştur (Karagözoğlu, 2016; Köprülü ve diğ., 2018). Sınıf yönetim becerilerini oluşturan ögeler incelendiğinde daha çok sınıf içinde öğrencilerle iletişim ve ilişkiye odaklanıldığı görülmektedir. İnsanlar arası ilişki yönetimi; duyguları fark etmek, anlamak, yorumlamak ve kontrol edebilmek üzerinde durmaktadır. Kendisinin ve öğrencilerinin duygularının farkına varamayan öğretmenin eksik kaldı̆̆ söylenebilir. Duygusal zekâ da "duyguları tanımak, yönetmek, karşıdaki kişi ve kişilerin duygularını fark etmek, sosyal ilişkileri yönetebilmek" becerilerini içermektedir (Tuyan ve Beceren, 2004, s.38). George (2000) ise duygusal zekânın, diğer bir deyişle kendinin ve diğerlerinin ruh hallerini ve duyguları anlama ve yönetme becerisinin, organizasyonlarda etkili liderliğe katkıda bulunduğunu öne sürmektedir. Benzer olarak Rosete ve Ciarrochi (2005) de daha 
yüksek duygusal zekâ ile liderliğin ilişkili olduğunu belirtmiştir. Yapılan çalışmalara paralel olarak Acar (2002) da duygusal zekâ ile liderlik davranışları arasında pozitif ilişki olduğunu vurgulamaktadır. Bununla birlikte duygusal zekâsı yüksek öğretmenler, öğrencileriyle ilişkisini kuvvetlendirip öğrencinin kendine güvenini artırarak sağlıklı nesiller yetiştirebilmektedirler. Bu nedenle, öğretmenin yönetim becerilerini göstermesinin duygusal zekâyı oluşturan öğelerle de örtüştüğü söylenebilir. Yüksek sınıf yönetim becerileri olan öğretmenler zamanını verimli kullanır; çocukların stresten uzak, paylaşımcı, etkin, hoşgörülü bir eğitim almalarını sağlar. Benzer şekilde bir başka çalışmada (Tunca, 2010) öğretmenlerin sınıf yönetim beceri düzeyleri ile duygusal zekânın alt boyutlarından iyimserlik/ruh halini düzenleme düzeyleri arasında pozitif yönde anlamlı ilişki bulunmuştur. Denizel Güven ve Cevher'e (2005) göre de öğretmenler, sınıf yönetim becerilerini kullanırken çocukların duygularını aktarabilme, paylaşmayı öğrenme gibi durumları dikkate almalıdır. Bu anlamda duygusal zekâ ile sınıf yönetim becerilerinin ilişkili çıkması kuramsal olarak anlamlıdır. Özdevecioğlu ve diğerleri (2014) ise duygusal zekânın çalışanlar üzerindeki kötü niyetli yönetim algısının negatif tesirini küçülttüğü ya da tamamıyla yok ettiğini saptamıştır. Mevcut çalışmada da öğretmenlerin duygusal zekâları ile sınıf yönetim becerilerinin pozitif ilişkili olduğu görülmüş̧ür. Ek olarak duyguları tanımak, yönetmek gibi süreçlerin alınan eğitimlerle daha etkili hale gelebildiği düşünülmektedir. Örneğin Köprülü ve diğerleri (2018) duygusal zekâ eğitimi alan öğretim elemanlarının almayanlara göre sınıf yönetim beceri puanlarının daha yüksek olduğunu belirtmektedir.

Araştırmanın bağımsız değişkenleri olan öz yeterlik ve duygusal zekâ arasında orta düzeyde, pozitif, anlamlı ilişki bulunmaktadır. Bir başka deyişle, bireyin duygusal zekâsının güçlenmesi, öz yeterliğin de geliştiğini göstermektedir. Dolayısıyla öz yeterlik ve duygusal zekâ arasında pozitif yönde ve anlamlı ilişkinin çıkması teorik olarak anlaşılabilirdir. Alan yazın çalışmaları irdelendiğinde duygusal zekâyla öz yeterlik arasında pozitif yönde anlamlı ilişkiler bulunmaktadır (Abdolvahabi ve diğ., 2012; Amirian ve Behshad, 2016; Çelik A ğırman ve Naktiyok, 2018; Di Fabio ve Palazzeschi, 2008; Hashemi ve Ghanizadeh, 2011; Karamehmetoğlu, 2017; Öcal ve Şenel, 2016; Özbezek ve Paksoy, 2017; Ramchunder ve Martins, 2014; Rastegar ve Memarpour, 2009; Sert ve Traş, 2019; Sarkhosh ve Rezaee, 2014; Şenel, 2015; Şenel ve diğ., 2014; Wu ve diğerleri, 2019). Örneğin, Hashemi ve Ghanizadeh'e (2011) göre duygusal zekâ bileşenleri arasında kendini gerçekleştirme ve stres toleransının öğrencilerin öz yeterliliğinin olumlu yordayıcıları olduğu ortaya koyulmuştur. Öğretmenler açısından ele alındığında kendini gerçekleştiren ve stres toleransı yüksek 
öğretmenin öz yeterlik düzeylerini açıklama gücünün daha fazla olacağı düşünülebilir. Sert ve Traş'a (2019) göre ise duygusal ve akademik öz yeterlik ile duygusal zekânın alt boyutları arasında; sosyal öz yeterlik ile duygusal zekânın bazı boyutlar arasında anlamlı ilişki tespit edilmiştir. Ramchunder ve Martins'in (2014) çalışmasında ise duygusal zekâ ile öz yeterlik ve liderlik etkinliği arasında pozitif bir ilişki bulunmuştur.

Mevcut araştırma sonuçları duygusal zekâ ve öz yeterliğin, sınıf yönetim becerilerini pozitif yönde yordadığını göstermektedir. Duygusal zekânın tek başına sınıf yönetim becerilerinin alt boyutları arasındaki yordayıcı gücüne bakıldığında "Fiziksel Düzen ve Plan Program Etkinlikleri” alt boyutunu daha az yordadığı; öz yeterlik devreye girdiğinde ise modelin “Fiziksel Düzen ve Plan Program Etkinlikleri” alt boyutunu yordama gücünün arttığı görülmüştür. Bununla birlikte, öz yeterliğin modele eklenmesiyle duygusal zekânın sınıf yönetim becerilerinin "Fiziksel Düzen ve Plan Program Etkinlikleri” alt boyutu üzerindeki yordayıcı etkisinin azaldığı ve anlamlılığını kaybettiği görülmüştür. "Fiziksel Düzen ve Plan Program Etkinlikleri”, duyguları kullanmanın değil, daha çok objektif olarak bireyin bu konudaki yeterliklerine olan inancını gerektiren bir boyuttur. Dolayısıyla öz yeterliğin modele eklenmesiyle modelin açıklanma gücünün artması; duygusal zekânın açıklama gücününse düşmesi ve anlamsızlaşması olağan görülmektedir. Bu durum öz yeterliğin tam aracılık etkisi olabileceğine işaret etmektedir (Hayes, 2013).

Sınıf yönetim becerilerinin "İlişki ve Davranış Düzenlemesi” alt boyutuna bakıldığında ise ilk adımda duygusal zekânın tek başına "İlişki ve Davranış Düzenlemesi" alt boyutundaki değişimi daha az yordadığı, öz yeterlik eklendiğinde ise modelin "İlişki ve Davranış Düzenlemesi” alt boyutundaki değişimi yordama gücünü arttırdığı görülmüştür. Bunun yanı sıra, öz yeterliğin modele eklenmesiyle sınıf yönetim becerilerinin "İlişki ve Davranış Düzenlemesi” alt boyutu ile duygusal zekâ arasındaki ilişkideki değişimin açıklanma gücünün düştüğü ancak anlamlılığın korunduğu görülmüştür. Devam eden bu anlamlı etkinin gerek sınıf yönetim becerilerinin "İlişki ve Davranış Düzenlemesi” alt boyutunun gerekse duygusal zekânın daha çok beşeri faktörlerden, diğer bir deyişle insan ilişkilerinden etkilenmesinin bir sonucu olabileceği düşünülmektedir.

Son olarak belirtilen bağımsız değişkenlerin toplam sınıf yönetim becerilerini açıklama gücü incelenmiştir. Mevcut araştırma sonuçlarına göre duygusal zekâsı yüksek öğretmenlerin öğretmen-öğrenci ilişkisini kuvvetlendirdiğgi, öğrencinin kendine güvenini artırarak sağlıklı nesiller yetiştirdiği çıkarımında bulunulabilir. Yapılan araştırmalar incelendiğinde alan yazında yer alan diğer çalışmalar tarafından da elde edilen bu bulgunun 
desteklendiği görülmektedir (Çakar ve Arbak, 2003; Delice ve Günbeyi, 2013; Tunca, 2010; Summak ve Özgan, 2007). Çakar ve Arbak (2003), yöneticinin duygusal zekâsı arttıkça, kendini izleyen grubu yalnızca bir üye olarak görmekten ziyade, onları bir birey olarak görmeye başladığını ve onların sorunlarıyla ilgilenme eğiliminde artış olduğunu ifade etmektedir. Ayrıca duygusal zekâ düzeyi fazla olan yöneticilerin çalışanları için daha çok ilham olduğu bilinmektedir. $\mathrm{Bu}$ çalışmada belirtilen yönetici-çalışan arasındaki ilişki, öğretmen ve öğrenciler arasındaki ilişki şeklinde düşünülebilir. Delice ve Günbeyi’nin (2013) çalışmasında ise liderlik davranışlarını genel ruh hali ve kişisel farkındalık boyutlarının açıkladığı görülmektedir. Summak ve Özgan'a (2007) göre ise yönetici kesimin birtakım duygusal, sosyal ve ruhsal zekâ yeterliklerinin yönetim süreç becerilerini yordadığı gözlenmektedir. Yapılan çalışmaların ortak noktası duygusal zekânın yöneticilik ve liderlik süreçlerine olumlu anlam yüklemeleridir. Dolayısıyla elde edilen bu bulgular mevcut araştırma sonuçlarıyla paralellik göstermektedir. Modele öz yeterliğin eklenmesiyle bağımsız değişkenlerin birlikte yordayıcı gücünün arttığı görülmektedir. Bir başka deyişle, duygusal zekânın verimli olduğu ve bunun öz yeterliği güçlendirdiği görülmektedir. Dikkat çeken bir diğer nokta, duygusal zekânın modele katkısının anlamlı olmasıyla birlikte sınıf yönetim becerileriyle ilişskilerini gösteren standartlaştırılmış regresyon katsayılarında öz yeterliğin modele eklenmesiyle yarıdan fazla bir düşüş yaşanmasıdır. Öz yeterliğin duygusal zekâ ile sınıf yönetim becerileri arasındaki ilişkide kısmi aracı etkisinin olabileceğine, diğer bir ifadeyle duygusal zekânın sınıf yönetim becerilerini öz yeterlik üzerinden dolaylı olarak etkileyebileceğine işaret etmektedir (Baron ve Kenny, 1986; Hayes, 2013).

Öz yeterlik ve duygusal zekânın sınıf yönetim becerilerini yordaması, öğretmenlerin öz yeterlik ve duygusal zekâlarındaki artışın sınıf yönetim becerilerindeki artışı açıkladığını göstermektedir. Bu durumda duygusal zekâsı ve öz yeterlik inancı yüksek öğretmenlerin sınıf yönetiminde de başarılı olduğu ve sınıflarda hedefledikleri kazanımlara ulaşılmasının kolaylaştığı, dolayısıyla öğretimde bir gelişmenin sağlandığı söylenebilir. Yapılan araştırma sonuçlarının elde edilen mevcut sonuçlarla paralel olduğu görülmektedir. Duygusal zekâ eğitimi alan öğretim elemanlarının almayanlara göre sınıf yönetim becerileri puanları daha yüksek olmakta (Köprülü ve diğg., 2018), duygusal zekâ ile liderlik davranışları arasında pozitif ilişki bulunmakta (Acar, 2002) ve öğretimsel liderlik, öz yeterliği yordamaktadır (Sı̆̆rı, Tabak ve Güngör, 2012). Karamehmetoğlu (2017) da duygusal zekânın öz yeterliliğin sınıf yönetimine dair alt boyutlarının yordayıcısı olduğunu göstermiştir. Mevcut çalışmada 
duygusal zekâ ve öz yeterliğin sınıf yönetim becerilerini yordama gücü dikkate alındığında bu çalışmanın mevcut çalışmayla örtüştüğü söylenebilir.

Mevcut çalışmada duygusal zekânın sınıf yönetimi üzerindeki etkisi öz yeterlik değişkenini aracı kılarak daha da belirgin hale gelmektedir. Alan yazın çalışmaları incelendiğinde duygusal zekânın öz yeterliği güçlendirdiği görülmüştür (Hashemi ve Ghanizadeh, 2011; Karamehmetoğlu, 2017). Bu çalışmanın aksine Özbezek ve Paksoy'a (2017) göre ise "Duygusal Zekâ ve Liderlik Etme Motivasyonu" arasında öz yeterliğin aracılık rolüyle ilgili anlamlı ilişki bulunmamaktadır. Farklı sonuçlar elde edilmenin sebebi olarak Özbezek ve Paksoy’un (2017) çalışmasında öğrencilerle çalışılması düşünülebilir.

Yapılan araştırma Kastamonu ili Milli Eğitim Müdürlüğü'ne bağlı devlet okullarında çalışan öğretmenlerle sınırlıdır. Araştırma sonuçlarından yola çıkılarak araştırmacılar ve uygulayıcılar için aşağıdaki önerilere yer verilmiştir:

1) Araştırmada öz yeterlik ve duygusal zekânın sınıf yönetim becerilerini yordama düzeyi ve öz yeterliğin aracı rolü incelenmiştir. Sınıf yönetiminde açıklanamayan diğer kısım için daha fazla değişkenin olduğu modeller test edilmelidir. Bu anlamda bireysel değişkenlere ek olarak okulun yönetsel ve eğitsel faaliyetlerinde söz sahibi olan okulun tüm paydaşlarını ele alan okul iklimi gibi örgütsel değişkenlerin modele eklenmesiyle aradaki ilişkilerin ve aracı rollerin test edilmesi önerilebilir.

2) Alan yazın çalışmalarında daha çok nicel araştırma yöntemlerinin kullanıldığı görülmüştür. Sınıf yönetim becerileri, duygusal zekâ ve öz yeterlik ile ilgili nitel araştırma yöntemlerinin benimsendiği farklı çalışmalar yapılabilir.

3) Duygusal zekâ ve öz yeterlik inancının sınıf yönetim becerilerinde belirleyici değişkenler olduğu görülmüştür. Bu nedenle gerek hizmet öncesinde gerekse hizmet içinde öğretmenlerin bu özelliklerini güçlendirici eğitim çalışmalarına ağırlık verilebilir.

4) Liderlikle ilgili görevlerinin bir parçası olarak okul yöneticilerine öğretmenlerin öz yeterlik inançları ve duygusal zekâlarını desteklemek adına öğretim süreçlerini ve okul kültürünü geliştirmeye yönelik yeni fikirler sunmaları yönünde onları teşvik etmesi önerilebilir. 
Etik Kurul İzin Bilgisi: Bu makale Dr. Hasan KAVGACI danışmanlığında hazırlanan “Öğretmenlerin Duygusal Zekâları ve Öz Yeterlik Inançları ile Sınıf Yönetimi Becerileri Arasındaki İlişkinin İncelenmesi” isimli tez çalışmasından üretilmiştir. (Tez No: 534921). Çalışmanın bir kısmı ise, 18-22 Nisan 2018 tarihleri arasında 27. Uluslararası Ĕ̆itim Bilimleri Kongresi’nde sözlü bildiri olarak sunulmuştur.

Yazar Çıkar Çatışması Bilgisi: Yazarlar herhangi bir çıkar çatışması beyan etmemektedir

Yazar Katkısı: Her iki yazar bu makaleye eşit katkı sağlamıştır. 


\section{Kaynakça}

Abdolvahabi, Z., Bagheri, S., Haghighi, S. \& Karimi, F. (2012). Relationship between emotional intelligence and self-efficacy in practical courses among physical education teachers. European Journal of Experimental Biology, 2(5), 1778-1784.

Abu Tineh, A. M., Khasawneh, S. A. \& Khalaileh, H. A. (2011). Teacher self-efficacy and classroom management styles in Jordanian schools. Management in Education, 25(4), 175-181. doi: 10.1177 / 0892020611420597

Acar, F. (2002). Duygusal zekâ ve liderlik. Erciyes Üniversitesi Sosyal Bilimler Enstitüsü Dergisi, 12(12), 53-68.

Akgemci, T. ve Doğanalp, B. (2008). Duygular ve liderlik: Duygusal zekânın rolü. M.Ş. Şimşek, A. Çelik (Ed.). Çă̆daş yönetim ve örgütsel başarım içinde (s.185-206). Konya: Eğitim Kitabevi Yayınları.

Aksoy, R. (2011). Ortaöğretim ögretmenlerinin ögretmen öz yeterlik ve yapılandırmacı ögrenme ortamı düzenleme becerilerine yönelik algıları (Manisa ili örneği). (Yüksek lisans tezi). Yükseköğretim Kurulu Ulusal Tez Merkezi’nden edinilmiştir (Tez No: 326003).

Amirian, S.M.R. \& Behshad, A. (2016). Emotional intelligence and self-efficacy of Iranian teachers: A research study on university degree and teaching experience. Journal of Language Teaching and Research, 7(3), 548-558. doi: http://dx.doi.org/10.17507/jltr.0703.16

Babaoğlan, E. ve Korkut, K. (2010). Sınıf öğretmenlerinin öz yeterlik inançları ile sınıf yönetim beceri algıları arasındaki ilişki. İnönü Üniversitesi Eğitim Fakültesi Dergisi, 11(1), 1-19.

Baloğlu, N. (2001). Etkili sınıf yönetimi. Ankara: Baran Ofset Matbaacılık.

Bandura, A. (1982). Self-efficacy mechanism in human agency. American Psychologist, 37(2), 122-147. doi https://doi.org/10.1037/0003-066X.37.2.122

Baron, R. M. \& Kenny, D. A. (1986). The moderator-mediator variable distinction in social psychological research: Conceptual, strategic, and statistical considerations. Journal of Personality and Social Psychology, 51, 1173-1182. doi: 10.1037 // 00223514.51.6.1173 
Bar-On, R. (2006). The Bar-On model of emotional-social intelligence (ESI). Psicothema, $18(1), 13-25$.

Başar, H. (2014). Sınıf yönetimi. Ankara: Anı Yayıncılık.

Batar, M. ve Aydın, İ. S. (2014). Türkçe öğretmeni adaylarının yazılı anlatım öz yeterlik inançlarının değerlendirilmesi. International Journal of Language Academy, 2(4), 579-598.

Bay, D. N. (2020). Investigation of the relationship between self-efficacy belief and classroom management skills of preschool teachers with other variables. International Electronic Journal of Elementary Education, 12(4), 335-348. doi:10.26822/iejee.2020459463

Bozbaş, Y. (2015). Sınıf öğretmenlerinin öz yeterlilik inançlarl ve sinıf yönetimi beceri algıları arasındaki ilişki (Yüksek lisans tezi). Yükseköğretim Kurulu Ulusal Tez Merkezi'nden edinilmiştir (Tez No: 407057).

Çakar, U. ve Arbak, Y. (2003). Dönüşümcü liderlik duygusal zekâ gerektirir mi? Yöneticiler üzerinde örnek bir çalışma. Dokuz Eylül Üniversitesi İktisadi İdari Bilimler Fakültesi Dergisi, 18(2), 83-98.

Çapa, Y., Çakıroğlu, J. ve Sarıkaya, H. (2005). The development and validation of a Turkish version of the teachers' sense of efficacy scale. Education and Science, 30(137), 7481.

Çelik Ağırman, Ü. H. ve Naktiyok, A. (2018). Öz yeterlilik algısı bağlamında duygusal zekâ özellikleri ve girişimcilik niyeti. Journal of Social and Humanities Sciences Research, 5(28), 3253-3262.

Çelik, O. (2019). İlkokul ve ortaokul öğretmenlerinin öz yeterlilikleri ile sınıf yönetimi becerileri arasındaki ilişkinin incelenmesi (Yüksek lisans tezi). Yükseköğretim Kurulu Ulusal Tez Merkezi’nden edinilmiştir (Tez No: 553475).

Çelik, V. (2013). Sınıf yönetimi. Ankara: Nobel Yayın Dağıtım.

Delice, M. ve Günbeyi, M. (2013). Duygusal zekâ ve liderlik ilişkisinin incelenmesi: Polis teşkilatı örneği. Atatürk Üniversitesi İktisadi ve İdari Bilimler Dergisi, 27(1), 209239. 
Delson, K. M. (1982). A three dimensional approach to evaluating teaching performance, Paper presented At The Annual Convention Of The American Council On The Teaching For Foreign Languages, New York.

Demir, T. (2015). Okul öncesi ögrretmenlerinin öz yeterlik algılarının ve sınıf yönetimi stratejilerinin çocuk-öğretmen ilişkileri üzerindeki etkileri (Yüksek lisans tezi). Yükseköğretim Kurulu Ulusal Tez Merkezi’nden edinilmiştir (Tez No: 423431).

Demirtaş, H. (2015). Sınıf yönetiminin temelleri. H. Kıran ve K. Çelik (Ed.) içinde, Etkili sinıf yönetimi (s. 1-32). Ankara: Anı Yayıncıl1k.

Deniz, M. E., Özer, E. ve Işık, E. (2013). Duygusal zekâ özelliği ölçeği-kısa formu: Geçerlik ve güvenirlik çalışması. Eğitim ve Bilim, 38(169), 407-419.

Denizel Güven, E. ve Cevher, F. N. (2005). Okulöncesi öğretmenlerinin sınıf yönetim becerilerinin çeşitli değişkenler açısından incelenmesi. Pamukkale Üniversitesi Ĕ̈itim Fakültesi Dergisi, 2(18), 1-22.

Di Fabio, A. \& Palazzeschi, L. (2008). Emotional intelligence and self-efficacy in a sample of Italian high school teachers. Social Behavior and Personality, 36(3), 315-326. doi: 10.2224 / sbp.2008.36.3.315

Eker, C. (2014). Sınıf öğretmenlerinin öz yeterlik inanç düzeyleri üzerine bir araştırma. Uşak Üniversitesi Sosyal Bilimler Dergisi, 7(1), 162-178.

Epstein, A. \& Willhite, G. L. (2015). Teacher efficacy in an early childhood professional development school. International Electronic Journal of Elementary Education, 7(2), 189-198.

Erdoğan, İ. (2015). Sınıf yönetimi: Ders, konferans panel ve seminer etkinliklerinde başarının yolları. İstanbul: Alfa Basım Yayım Dağıtım.

Geçikli, F. (2013). Halkla ilişkiler ve iletişim. İstanbul: Beta Yayıncılık.

George, J. M. (2000). Emotions and leadership: The role of emotional intelligence. Human Relations, 53(8), 1027-1055. doi:10.1177/0018726700538001

Goleman, D. (2010). Duygusal zekâ (EQ), neden IQ'dan daha önemlidir? (B.Seçkin Yüksel Çev.). İstanbul: Varlık Yayınları. 
Goleman, D., Benett, L. \& Barlow, Z. (2012). Ecoliterate: How educators are cultivating emotional, social and ecological intelligence. San Francisco: Jossey-Bass. http://ebookcentral.proquest.com adresinden alınmıştır.

Grant, C. A. \& Gillette, M. (2006). A candid talk to teacher educators about effectively preparing teachers who can teach everyone's children. Journal of Teacher Education, 57(3), 292-299. doi: 10.1177 / 0022487105285894

Gültekin, M. (2020). Değişen toplumda eğitim ve öğretmen nitelikleri. Anadolu Journal of Educational Sciences International, 10(1), 654-700. doi: 10.18039/ajesi.682130

Güneş, A. M. (2016). Sınıf öğretmenlerinin sınıf yönetim becerileri, teknoloji kullanımları ve öz yeterlik inançları arasındaki ilişki (Doktora tezi). Yükseköğretim Kurulu Ulusal Tez Merkezi’nden edinilmiştir (Tez No: 450126).

Hashemi, M. R. \& Ghanizadeh, A. (2011). Emotional intelligence and self-efficacy: A case of Iranian EFL University students. International Journal of Linguistics, 3(1), 1-16. doi: 10.5296/ijl.v3i1.877

Hayes, A. F. (2013). Introduction to mediation, moderation, and conditional process analysis: A regression-based approach. New York, NY: The Guilford Press.

Hoy, W. K. ve Miskel, C. G. (2012). Eğitim yönetimi: Teori, araştırma ve uygulama (S. Turan Çev. Ed.). Ankara: Nobel Akademi Yayınları.

İpek, S. ve İpek, C. (2015). Temel eğitimde görev yapan öğretmenlerin sınıf yönetimi öz yeterlik inançları ve mesleki tutumları. (Rize ili örneği), EJEDUS Elektronik Ĕgitim Bilimleri Dergisi, 4(8), 169-190.

Karagözoğlu, N. (2016). Sosyal bilgiler öğretmenlerinin duygusal zekâ yeterliklerini mesleğinde kullanma düzeyleri ile benimsedikleri sınıf yönetim modelleri arasındaki ilişki. Akademik Sosyal Araştırmalar Dergisi, 4(29), 269-287. doi: 10.16992/ASOS. 1240

Karamehmetoğlu, M. (2017). Beden eğitimi öğretmenlerinin duygusal zekâ düzeylerinin mesleki öz yeterlik ve problem çözme becerilerini belirlemedeki rolünün incelenmesi (Yüksek lisans tezi). Yükseköğretim Kurulu Ulusal Tez Merkezi’nden edinilmiştir (Tez No: 469599). 
Kavgacı, H. (2014). Illköğretim kurumu öğretmenlerinin işle bütünleşme düzeylerinin bireysel ve örgütsel değişkenlerle ilişkisi (Doktora tezi). Yükseköğretim Kurulu Ulusal Tez Merkezi'nden edinilmiştir (Tez No: 366266).

Kavgacı, H. ve Çalık, T. (2017). Öğretmenlerin işle bütünleşme düzeylerinin örgütsel ve bireysel değişkenlerle ilişkisi: Bir çoklu aracılık modeli. Kuram ve Uygulamada Ĕ̌itim Yönetimi, 23(2), 223-248. doi: 10.14527/kuey.2017.008

Koçoğlu, Z. (2011). Emotional intelligence and teacher efficacy: A study of Turkish EFL pre-service teachers. Teacher Development, 15(4), 471-484. doi: 10.1080/13664530.2011.642647

Korkmaz, İ. (2013). Sosyal öğrenme kuramı. B. Yeşilyaprak (Ed.). Eğitim psikolojisi: Gelişim-ögrenme-ögretim içinde (s. 245 - 270). Ankara: Pegem Akademi Yayıncılık.

Korkut, K. (2009). Sını öğretmenlerinin öz yeterlik inançları ile sınıf yönetim beceri algıları arasındaki ilişki (Yüksek lisans tezi). Yükseköğretim Kurulu Ulusal Tez Merkezi’nden edinilmiştir (Tez No: 250873).

Köprülü, O., Turhan, M. ve Helvacı, İ. (2018). Öğretim elemanları ve öğretmenlerin duygusal zekâ düzeyleri ve sınıf yönetim becerileri açısından karşılaştırılması. The Journal of Academic Social Science Studies, 71, 419-426. doi: http://dx.doi.org/10.9761/JASSS7735

Loflin, D. C. \& Barry, C. T. (2016). 'You can't sit with us:' Gender and the differential roles of social intelligence and peer status in adolescent relational aggression. Personality and Individual Differences, 91, 22-26. doi: https://doi.org/10.1016/j.paid.2015.11.048

Luthans, F. (2002). Positive organizational behavior: Developing and managing psychological strengths. The Academy of Management Executive, 16(1), 57-75.

MacKinnon, D. P., Lockwood C. M. \& Williams, J. (2004). Confidence limits for the indirect effect: Distribution of the product and resampling methods. Multivariate Behavioral Research, 39(1), 99-128. doi: 10.1207 / s15327906mbr3901_4

Milli Eğitim Bakanlığı (MEB), (2017). Öğretmenlik mesleği genel yeterlikleri. Ankara: Öğretmen Yetiştirme ve Geliştirme Genel Müdürlüğü. http://oygm.meb.gov.tr/www/ogretmenlik-meslegi-genel-yeterlikleri/icerik/39 adresinden alınmıştır. 
Öcal, K. ve Şenel, E. (2016). Duygusal zekânın sosyal destek algısı üzerindeki etkisi: Öz yeterlik inancının aracı rolü. Sosyal ve Beceri Bilimler Araştırmaları Dergisi, 17(36), 138-154.

Özbezek, B. D. ve Paksoy, H. M. (2017). Liderlik etme motivasyonu ve duygusal zekâ arasındaki ilişkide öz yeterliliğin rolü üzerine bir araştırma. International Journal of Disciplines Economics \& Administrative Sciences Studies, 3(4), 248-269.

Özçelik, F. (2019). Okul öncesi ögretmenlerinin sınıf yönetimi becerileri ile öz yeterlikleri arasındaki ilişki (Yüksek lisans tezi). Yükseköğretim Kurulu Ulusal Tez Merkezi'nden edinilmiştir (Tez No: 563079).

Özdevecioğlu, M., Akın, M. Karaca, M. ve İştahlı, B. (2014). Kötü niyetli yönetim algılamasının çalışanların performansları üzerindeki etkisinde duygusal zekânın rolü. Çankırı Karatekin Üniversitesi İktisadi ve İdari Bilimler Fakültesi Dergisi, 4(1), 118.

Petrides, K. V. \& Furnham, A. (2001). Trait emotional intelligence: Psychometric investigation with reference to established trait taxonomies. European Journal of Personality, 15(6), 425-448. doi: 10.1002 / per. 162

Porter, T. H. (2011). The power of transformational leadership: The effect on self-efficacy, spirituality, and MTL (Doctoral dissertation). Retrieved from ProQuest Dissertations and Theses database. (UMI: 3480381).

Ramchunder, Y., \& Martins, N. (2014). The role of self-efficacy, emotional intelligence and leadership style as attributes of leadership effectiveness. SA Journal of Industrial Psychology, 40(1), 1-11. doi: http://dx.doi.org/10.4102/sajip.

Rastegar, M. \& Memarpour, S. (2009). The relationship between emotional intelligence and self-efficacy among Iranian EFL teachers. Science Direct, 37, 700-707.

Robbins, S. P. ve Judge, T. A. (2015). Örgütsel davranış (İ.Erdem Çev,Ed.). Ankara: Nobel Akademik Yayıncılık.

Rosete, D. \& Ciarrochi, J. (2005). Emotional intelligence and its relationship to workplace performance outcomes of leadership effectiveness. Leadership \& Organization Development Journal, 26(5), 388-399. doi: 10.1108/01437730510607871

Ross, J. A. (1992). Teacher efficacy and the effects of coaching on student achievement. Canadian Journal of Education, 17(1), 51-65. 
Salovey, P. \& Mayer, J. D. (1990). Emotional intelligence. Imagination, cognition and personality, 9(3), 185-211. doi: https://doi.org/10.2190\%2FDUGG-P24E-52WK$6 \mathrm{CDG}$

Sarıtaş, M. (2003). Sınıf yönetimi ve disiplinle ilgili kurallar geliştirme. L. Küçükahmet (Ed.). Sınıf Yönetiminde Yaklaşımlar içinde (s.43-86). Ankara: Nobel Yayın Dağıtım.

Sarkhosh, M. \& Rezaee, A. A. (2014). How does university teachers' emotional intelligence relate to their self-efficacy beliefs? Porta Linguarum, 21, 85-100.

Schwarzer, R., Antoniuk, A. \& Gholami, M. (2015). A brief intervention changing oral selfcare, self-efficacy, and self-monitoring. British Journal of Health Psychology, 20, 56-67. doi: 10.1111/bjhp.12091

Semerci, D. ve Uyanık Balat, G. (2018). Okul öncesi öğretmenlerinin sınıf yönetimi becerileri ve öz yeterlik algıları arasındaki ilişkinin incelenmesi. İnönü Üniversitesi Ĕ̌itim Fakültesi Dergisi, 19(3), 494-514. doi: 10.17679/inuefd.394585

Senemoğlu, N. (2013). Gelişim, ögrenme ve öğretim: Kuramdan uygulamaya. Ankara: Yargı Yayınevi.

Sert, M. ve Traş, Z. (2019). Ergenlerin duygusal zekâ düzeyleri ile öz yeterlik algıları arasındaki ilişkinin incelenmesi. Manas Sosyal Araştırmalar Dergisi, 8(1), 12391254. doi: https://doi.org/10.33206/mjss.500797

Sığrı, Ü., Tabak, A. ve Güngör, H. (2012). Öz yeterliğin dönüştürücü liderlik üzerine etkisi: Kamu sektöründe bir araştırma. Istanbul Ticaret Üniversitesi Sosyal Bilimler Dergisi, 9(17), 51-66.

Summak, M. S. ve Özgan, H. (2007). İlköğretim okulu müdürlerinin yönetim süreçlerini kullanma etkinlikleri ile bazı duygusal sosyal ve ruhsal yeterlilikleri arasındaki ilişkinin incelenmesi (Kilis ili örneği). Türk Ĕ̆itim Bilimleri Dergisi, 5(2), 261-288.

Şenel, E. (2015). Beden ĕgitimi ve spor yüksekokulunda öğrenim gören ögrrencilerin sosyal destek algllarl, genel öz yeterlik inançları ve duygusal zekâ düzeylerinin değerlendirilmesi (Yüksek lisans tezi). Yükseköğretim Kurulu Ulusal Tez Merkezi'nden edinilmiştir (Tez No: 419983).

Şenel, E., Adiloğulları, İ. \& Ulucan H. (2014). Examination of emotional intelligence level, teacher's self-efficacy beliefs and general self-efficacy beliefs of teachers. Nigde University Journal of Physical Education and Sport Sciences, 8(2), 22-232. 
Taş, A. (2015). Sınıf yönetimini etkileyen faktörler. H. Kıran ve K. Çelik (Eds.). Etkili Sınıf Yönetimi içinde (s.33-58). Ankara: Anı Yayıncılık.

Tok, T. N., Tok Ş. \& Doğan Dolapçioğlu, S. (2013). The relationship between emotional intelligence and classroom management approaches of primary school teachers. Educational Research, 4(2), 134-142. doi: 10.1002/pits.22218

Toytok, E. H. (2013). Öğretmenlerin duygusal zekâ yeterliklerini sınıf yönetimi sürecinde kullanma düzeyleri: Sakarya ili örneği. Anadolu Ĕ̆itim Liderliği ve Öğretim Dergisi, l(1), 27-43.

Tschannen-Moran, M. \& Hoy, A. W. (2001). Teacher efficacy: Capturing and elusive construct. Teaching and Teacher Education, 17(7), 783-805. doi: 10.1016/S0742051X(01)00036-1

Tschannen-Moran, M., Woolfolk Hoy, A. \& Hoy, W. K. (1998). Teacher efficacy: Its meaning and measure. Review of Educational Research, 68(2), 202-248. doi: $10.3102 / 00346543068002202$

Tunca, Ö. (2010). Duygusal zekâ düzeylerinin sınıf yönetim becerilerine etkisi ve bir araştırma (Yüksek lisans tezi). Yükseköğretim Kurulu Ulusal Tez Merkezi’nden edinilmiştir (Tez No: 264508).

Tuyan S. ve Beceren, E. (2004). Sınıf yönetiminde duygusal zekâ becerilerinin kullanılması. Çukurova Üniversitesi Ĕ̈itim Fakültesi Dergisi, 2(28), 37-42.

Türk Eğitim Derneği (TED). (2009). Öğretmen yeterlikleri. Ankara: Adım Okan.

Üredi, I. ve Üredi, L. (2006). Sınıf öğretmeni adaylarının cinsiyetlerine, bulundukları sınıflara ve başarı düzeylerine göre fen öğretimine ilişkin öz yeterlik inançlarının karşılaştırılması. Yeditepe Üniversitesi Ĕ̈itim Fakültesi Dergisi, 1(2), 1-8.

Valente, S., Veiga-Branco, A., Rebelo, H., Lourenço, A. A. \& Cristóvão, A. M. (2020). The relationship between emotional intelligence ability and teacher efficacy. Universal Journal of Educational Research, 8(3), 916-923. doi: 10.13189/ujer.2020.080324

Woolfolk Hoy, A. \& Spero, R. B. (2005). Changes in teacher efficacy during the early years of teaching: A comparison of four measures. Teaching and Teacher Education, 21, 343-356. 
416 H.Sağlam ve H.Kavgac1/ Pamukkale Üniversitesi Eğitim Fakültesi Dergisi, 52, 389-416, 2021

Wu, Y., Lian, K., Hong, P., Liu, S., Lin, R., \& Lian, R. (2019). Teachers' emotional intelligence and self-efficacy: Mediating role of teaching performance. Social Behavior and Personality: An International Journal, 47(3), e7869. https://doi.org/10.2224/sbp.7869

Yalçınkaya, M. ve Tonbul, Y. (2002). İlköğretim okulu sınıf öğretmenlerinin sınıf yönetim becerilerine ilişkin algı ve gözlemleri. Ege Ĕgitim Dergisi, 1(2), 96-103.

Yüksel, A. (2013). Sinıf ögretmenlerinin sinıf yönetim becerilerinin değerlendirilmesi (Afyonkarahisar ili örneği) (Doktora tezi). Yükseköğretim Kurulu Ulusal Tez Merkezi’nden edinilmiştir (Tez No: 349099). 


\title{
The Mediating Role of Teachers' Self-Efficacy Beliefs in the Relationship Between Their Emotional Intelligence and Classroom Management Skills*
}

\author{
Hediye SAĞLAM ${ }^{* *}$ Hasan KAVGACI***
}

• Received: 29.07.2020 • Accepted: 08.01.2021 • First Online: 09.01.2021

\begin{abstract}
This study examines the relationships between emotional intelligence and classroom management skills of preschool and primary school teachers and the mediating role of self-efficacy in this relationship. The relational screening model was used in the study, which was designed in quantitative research design. The study group of the research consists of 376 pre, primary, and secondary school teachers. $68 \%$ of the participants with an average age of $37(S D=8,7)$ are women, and $32 \%$ are men. As a data collection tool, personal information form, Classroom Management Skills Scale, Emotional Intelligence Scale, and Teacher Self-Efficacy Scale were used. Data were analyzed using the SPSS-21 package program. In the study, Pearson Moment Correlation Coefficients were calculated to determine the relationships between variables, and multiple regression analysis was performed to examine the prediction situation. In the study, the mediating effect was analyzed using the PROCESS macro for SPSS. When the research findings were evaluated, moderate, positive, and significant relationships were found between variables. It was also seen that emotional intelligence and self-efficacy beliefs explained $48 \%$ of teachers' classroom management skills. The contribution of both independent variables to the model, and the mediating effect of self-efficacy were significant.
\end{abstract}

Keywords: Classroom management skills, emotional intelligence, self-efficacy, mediation, teacher

Cited:

Sağlam, H., \& Kavgac1, H. (2021). The mediating role of teachers' self-efficacy beliefs in the relationship between their emotional intelligence and classroom management skills. Pamukkale University Journal of Education, 52, 389-416.doi:10.9779.pauefd.775406

\footnotetext{
* This article was adapted from the master thesis named "Examining the Relationship Between Teachers' Emotional Intelligence and Self-Efficacy Beliefs and Classroom Management Skills" (Thesis No: 534921). A part of the study was presented as an oral presentation at the 27th International Educational Sciences Congress held between 18-22 April 2018.

** Lecturer, Kastamonu University Cide Rıfat Ilgaz Meslek Yüksekokulu, hdy.sglm@gmail.com ORCID: https://orcid.org/0000-0001-6025-7885

*** Dr., Ministry of National Education, Board of Education, hasank83@gmail.com ORCID: https://orcid.org/0000-00015016-7704
} 


\section{Introduction}

Classroom management is the process of providing a suitable environment for resources, people, teaching, and time management in the classroom (Çelik, 2013; Erdoğan, 2015). It is also described as the process of setting classroom rules (Çelik, 2013); and developing a positive learning environment by ensuring the systematic and conscious operation of elements in the classroom such as the effectiveness of the student, teacher, time, place, motivation, technology, curriculum, and teaching method (Baloğlu, 2001; Çelik, 2013; Sarıtaş, 2003; Taş, 2015; Yüksel, 2013). According to another definition, classroom management is "to lead students to achieve certain goals, to manage the total work and efforts for this, to use all kinds of resources in the classroom, to overcome the predicted difficulties, and to help students act collaboratively in the classroom" (Erdoğan, 2015, s. 13). Based on these definitions, classroom management can be explained as the process of teachers' using various tools, methods, techniques, and materials effectively considering students' needs in the education system and creating a positive classroom climate to guide students.

In creating a positive classroom climate, teachers should devote their lives to their students, direct students' movements, use technology, and have professional competence for child development. Additionally, for a positive climate in the classroom, teachers need to be able to conduct education in a planned manner, communicate in a learning-teaching environment, monitor and evaluate students, cooperate with the personnel, master the necessary legislation, and sustain their professional development [Türk Eğitim Derneği (TED), 2009]. Moreover, teachers' professional qualifications include effective classroom management (Gültekin, 2020). Reaching these competencies requires the development of teachers' managerial qualifications and their educational qualifications (Demirtaş, 2015) because good classroom management brings efficiency and success in teaching. Therefore, classroom management is seen as one of the main determinants in teaching effectiveness and success (Erdoğan, 2015). To be effective and efficient, teachers must plan and manage the teaching and learning environment healthily. With these skills, teachers enable students to be engaged in learning and decision-making processes while at the same time, they aim their students to be active in both academic and social processes. The students' thinking, opinion, and knowledge skills strengthen the classroom texture through the democratic management of the classroom (Grant \& Gillette, 2006). According to a study conducted by TED (2009), although most of the students emphasize that they come to the classroom lovingly and 
willingly, it is stated by teachers that students are not willing to learn. Another result of the study indicates that some of the students stated that they did not feel comfortable in the classroom, that they felt worthless in the teacher's eyes, that the teachers did not do the behaviors they expected from the students, and that they did not act fairly. Despite this situation, it is thought that students come to the classroom willingly and lovingly due to peer relationships. In such a situation, teachers should design the learning and teaching process to develop students' desire to learn by taking into account the child's age, developmental characteristics, interests, and individual differences. Developing students' desire to learn depends on the teachers' ability to affect student learning, that is, teacher competence in a sense (Epstein \& Willhite, 2015). As a summary of the studies discussed, it can be stated that classroom management skills are the set of competencies encompassing teachers serve as reflective and transfer their inner treasure to the classroom, which is the field of education, teaching and learning, by developing both children and themselves. It can be said that for teachers to use this area most effectively, they first need to lead the learning environment healthily and thus gain classroom management skills.

When using classroom management skills, teachers consider situations such as enabling children to express their emotions and gain a sense of sharing (Denizel Güven \& Cevher, 2005). In this context, it can be stated that teachers should have competencies, such as knowing themselves first and then valuing and respecting students [Milli Eğitim Bakanlığı (MEB), 2017]. It can be asserted that getting to know yourself and the people around you fully includes the cognitive, social, and emotional dimensions. In this respect, it can be said that a teacher who does not recognize his / her own emotions or is not aware of the emotions of his students is lacking, and one of the important competencies of classroom management skills is emotional intelligence. According to Koçoğlu (2011), it is usual to examine the relationship between classroom management and emotional intelligence as it is known that individuals with strong competencies also have strong emotional intelligence.

Emotional intelligence includes the skills of "recognizing and managing emotions, recognizing the feelings of the other person or people, and managing social relations" (Tuyan \& Beceren, 2004, p. 38). As a result of some research, it is stated that emotional intelligence has five critical components in the form of recognizing an individual's emotions, managing these emotions, motivating himself, recognizing the feelings of others, and developing successful relationships (Goleman, Bennet, \& Barlow, 2012). Considering these aspects, Salovey and Mayer (1990, p.189) define emotional intelligence as "the type of 
social intelligence that includes the ability to convey emotions, discriminate and use their knowledge." Similarly, Goleman (2010, p.62) says it means "being able to mobilize oneself, survive despite problems, and regulate mood." Furthermore, emotional intelligence includes coping with both individual factors and the environment by solving problems realistically and flexibly (Bar-On, 2006), understanding the emotions of the individual and others, and making sense of events (Geçikli, 2013, p.306). In the same way, it is accepted to encompass understanding information and emotional-mental development as a reflection of these (Akgemci \& Doğanalp, 2008) and manage all of these (Robbins \& Judge, 2015). People with high emotional intelligence reflect characteristics such as communication, empathy, control, harmony, cooperation, motivation, influencing others, and leadership to their environment (Tunca, 2010). Besides, it has been revealed that the ability to perceive, understand, express, classify, manage, and regulate emotional intelligence, has positive effects on teacher productivity (Valente, Veiga-Branco, Rebelo, Lourenço, \& Cristóvão, 2020). For this reason, it can be expressed that the management skills that teachers need to demonstrate in the classroom overlap with the elements that make up emotional intelligence. In this context, emotional intelligence, whose importance has been understood recently, is accepted as a significant variable that has been studied in terms of its relationship with classroom management (Denizel Güven \& Cevher, 2005; Karagözoğlu, 2016; Köprülü, Turhan, \& Helvacı, 2018; Özdevecioğlu, Akın, Karaca, \& İştahlı, 2014; Tok, Tok, \& Doğan Dolapçioğlu, 2013; Toytok, 2013; Tunca, 2010). Considering the teacher's ability to understand and manage the moods and emotions of both herself/himself and the students, it can be said that emotional intelligence contributes to leadership. In this context, George (2000) also argues that emotional intelligence contributes to effective leadership in organizations. Rosete and Ciarrochi (2005) explain that higher emotional intelligence is associated with higher leadership effectiveness. When all these studies are evaluated together, it is expected that there is a significant positive relationship between teachers' classroom management skills and their emotional intelligence.

As stated in the discussions above, classroom management skills are based on teaching-learning processes. In the teaching-learning process, the skills in which the teacher plays a role are specified as teacher competencies (MEB, 2017). In Ross's (1992) research, it was concluded that teachers who have personal competence have more student success in their classes. Considering that when teachers increase their self-confidence, they offer more effective educational opportunities. It can be presumed that one of the teachers' 
competencies in the teaching process is self-efficacy. Woolfolk Hoy and Spero (2005) found a moderate relationship between teacher efficacy and self-efficacy. The self-efficacy concept has come to the fore even more with the positive psychology trend in social sciences, especially in psychology (Luthans, 2002). According to Bandura (1982), self-efficacy belief is defined as the individuals' belief that they can do the behaviors that need to be done to cope with their situations. Besides, Batar and Aydın (2014) assert that an individual's certain thought about self-efficacy development is a skilled process that only concerns the individual itself and is open to exploration. In this context, teacher self-efficacy is the teacher's perception of his/her ability to organize activities required to fulfill the teaching job (Tschannen-Moran, Woolfolk Hoy, \& Hoy, 1998). However, self-efficacy is also defined as the success that the individuals see in themselves in overcoming the difficulties they will encounter (Senemoğlu, 2013); individuals' ability to realize how much the behavior they have done coincides with the behavior they should do (Korkmaz, 2013), the individuals' belief in their ability to perform a specific task (Aksoy, 2011), or the individuals' selfassessment of their ability to do a job (Hoy and Miskel, 2012). In the relevant literature, some studies reveal the relationship between both variables, which supports the assertion that individuals can improve their classroom management skills by using their self-efficacy (Abu Tineh, Khasawneh, \& Khalaileh, 2011; Babaoğlan \& Korkut, 2010; Demir, 2015; Güneş, 2016; İpek \& İpek, 2015; Özbezek \& Paksoy, 2017).

Considering the relationship between self-efficacy and emotional intelligence in the existing literature, it can be said that the feelings and thoughts of the individual strengthen their perceptions about themselves and their self-efficacy beliefs. Studies on educators show that there are positive relationships between the teachers' and university lecturers' selfefficacy, emotional intelligence and teacher competence (Abdolvahabi, Bagheri, Haghighi, \& Karimi, 2012; Amirian \& Behshad, 2016; Çelik Ağırman \& Naktiyok, 2018; Di Fabio \& Palazzeschi, 2008; Hashemi \& Ghanizadeh, 2011; Karamehmetoğlu, 2017; Ramchunder \& Martins, 2014; Rastegar \& Memarpour, 2009; Öcal \& Şenel, 2016; Özbezek \& Paksoy, 2017; Sert \& Traş, 2019; Sarkhosh \& Rezaee, 2014; Şenel, 2015; Şenel, Adiloğulları, \& Ulucan, 2014; Wu, Lian, Hong, Liu, Lin, \& Lian, 2019). This finding supports the idea that teachers can achieve success, especially in terms of classroom management, by improving their emotional intelligence and using their self-efficacy beliefs effectively. According to another study results, there are some significant and positive relationships both globally and in three dimensions (effectiveness in teaching strategy, effectiveness in classroom 
management, and student participation) between emotional intelligence and teacher selfefficacy (Di Fabio \& Palazzeschi, 2008). In this case, it is thought that emotional intelligence and self-efficacy beliefs will also affect teachers' classroom management skills.

As a result, because individuals' feelings, thoughts, and behaviors are different from each other, their perspectives on the events experienced also differ. These differences can sometimes bring about disagreement and uneasiness between individuals. Resolving conflicts and uneasiness and managing different situations require emotional intelligence. This situation can be achieved by the individual's self-improvement (Geçikli, 2013). The teacher should first understand the students and restructure the classroom environment to eliminate undesirable behaviors by ensuring that students develop creative thinking style and act as responsible individuals. To accomplish it, teachers need to pay attention to the feedback that may come from students in the learning and teaching process. Therefore, teachers have to act with an optimistic perspective, consider both their and children's feelings and thoughts, and manage the classroom with these skills. These skills are also highly similar to the factors that make up emotional intelligence (Tunca, 2010). However, teachers should raise people who can solve problems, investigate, criticize, access information, and have self-confidence. All these factors also depend on teachers' awareness of their self-efficacy beliefs (Eker, 2014). For this reason, well-trained teachers should have developed their self-efficacy beliefs (Üredi \& Üredi, 2006).

Teachers using classroom management skills effectively will ensure a positive atmosphere in the classroom. By using his time efficiently, teachers will help children receive education in a sharing, effective, and tolerant classroom environment free from stress. However, as Karamehmetoğlu (2017) claimed, with the development of emotional intelligence, teachers increase student participation in lessons, diversify their teaching strategies, provide more efficient classroom management, and strengthen their professional self-efficacy perceptions. This situation is an important convenience for classroom management. Since all these features constitute emotional intelligence dimensions, theachers' emotional intelligence will also help improve their classroom management skills. It can be stated that teachers who do not feel themselves sufficient in both classroom management and emotional intelligence will create insecurity, and this insecurity will affect the learning environment negatively.

In summary, it is thought that classroom management skills, emotional intelligence use, and self-efficacy beliefs are interrelated. At the same time, these are important factors in 
achieving educational goals. In this context, the related literature supports the assumption that there may be positive relationships between teachers' classroom management skills, emotional intelligence, and self-efficacy beliefs. However, it has been observed that the studies conducted generally examine the bilateral relationships between these variables, and no studies are examining the role of individual variables such as emotional intelligence and self-efficacy beliefs in explaining classroom management skills. Therefore, it is believed that when teachers realize the relationship between these variables, they will not only focus on plan-program activities, physical layout, the arrangement of teacher-student relations, use of time, classroom interaction, and Behavior Regulations but also try to improve their efforts on communication, empathy, control, harmony, cooperation, motivation, and influence others and to increase the belief that they can achieve success, especially in the education and training process.

\section{Purpose of the Research}

This study's main purpose is to examine the relationships between emotional intelligence and classroom management skills of preschool and primary school teachers and the mediating role of self-efficacy beliefs in this relationship. In this context, the answers to the following research questions will be sought within the scope of the research:

1. Are there any significant relationships between the teachers' emotional intelligence, self-efficacy beliefs, classroom management skills, and sub-dimensions?

2. Are the teachers' emotional intelligence and self-efficacy beliefs significant predictors of classroom management skills and their sub-dimensions?

3. Is the mediating role of self-efficacy beliefs in the relationships between teachers' emotional intelligence and their classroom management skills and their sub-dimensions significant?

\section{Method}

\section{Research Model}

This research is a quantitative study designed in a relational survey model that examines the relationships between teachers' emotional intelligence, self-efficacy beliefs, and classroom management skills. In the study, emotional intelligence is the independent variable, classroom management is the dependent variable, and self-efficacy belief is the mediator variable. 


\section{Participants}

The study group of the research consisted of 376 preschool and primary school teachers working in public schools affiliated to the Ministry of National Education in the provinces and districts of Kastamonu in the 2017-2018 academic year. The participants' average age is $37(S D=8.7)$. The $68 \%(\mathrm{n}=254)$ of the study group are women, $32 \%(\mathrm{n}=122)$ are men. $26 \%(\mathrm{n}=99)$ of the participants were between 22-30 years old, $44 \%(\mathrm{n}=165)$ between 31 40 years old, and $30 \%(n=112)$ from the age group of 41 and above. $14 \%$ of them $(n=54)$ were from pre-school while the others were from primary schools. $32 \%(\mathrm{n}=121)$ of them were the classroom teachers and the $54 \%(\mathrm{n}=201)$ were branch teachers. The $44 \%(\mathrm{n}=$ 166) had $1-10$ years, $35 \%(\mathrm{n}=130)$ had $11-20$ years, and $21 \%(\mathrm{n}=80)$ had 21 years and over seniority. Finally, $5 \%(\mathrm{n}=18)$ of them were college graduates while $89 \%(\mathrm{n}=336)$ had undergraduate, and $6 \%(n=22)$ had graduate degrees.

\section{Data Collection Tools}

The research data were collected through 3 different scales. In addition, a short section was added to the data collection form to collect demographic information about the participants.

\section{Emotional Intelligence Trait Scale-Short Form}

Emotional Intelligence Trait Scale-Short Form (DZÖÖ-SF) was originally developed by Petrides and Furnham (2001), and the validity and reliability analyses of the Turkish version were carried out by Deniz, Özer, and Işık (2013) on the data gathered from university students. This seven-point Likert-type scale consists of 20 items. The validity and reliability analyses repeated for the current study revealed that all the items explained $31 \%$ of the total variance resulting from EFA (Eigenvalue $=5.986$ ). After the 15 th item was removed from the scale due to its low factor loading (below .30), the remaining items showed factor loadings between $.34-.70$. Since the first factor of the scale explained more than $30 \%$ of the total variance, the total score was further analyzed. The Cronbach's alpha coefficient of the scale was .87 , and the corrected item-total correlations were between .35 and .65 .

\section{Teacher Self-Efficacy Belief Scale}

It was developed by Tschannen-Moran and Hoy (2001) and adapted to Turkish by Çapa, Çakıroğlu, and Sarıkaya (2005). The validity and reliability analysis of the short form was performed by Kavgac1 (2014). Nine-point Likert-type Teacher Self-Efficacy Scale (Short Form) consists of 12 items. According to the results of the second-level factor analysis, it was stated that the scale items were gathered around one dimension. The validity-reliability 
analyses repeated in the present study showed that the items were collected under one dimension and explained $54 \%$ of the total variance (Eigenvalue $=6.456$ ). The factor loads of the scale items were .67-.79; Cronbach's alpha internal consistency coefficient was .92; and item-total correlation coefficients were between $.61-.73$.

\section{Classroom Management Skills Scale}

The five-point Likert-type scale developed by Delson (1982) and adapted to Turkish by Yalçınkaya and Tonbul (2002) consists of 25 items. In the adaptation study to Turkish carried out by Korkut (2009), the scale was re-analyzed, and the number of items was reduced to 15. It was seen that the scale comprised of three sub-scales named "Physical Layout Plan Program Activities," "Arrangement of Teacher-Student Relationships," and "Classroom Interaction and Behavior Regulations with Time Use." In the current study, the validity and reliability analyses were repeated. When the component matrix was examined, $6^{\text {th }}$ and $10^{\text {th }}$ items were excluded from the scale due to substantial loadings (over .3) on more than one factor. Thus, the number of items in the scale decreased to 13 . The factor analysis conducted over 13 items revealed that the second and third dimensions discussed by Korkut (2009) were gathered around one dimension. The first dimension was named "Relationship and Behavior Regulation" (explained variance $=26 \%$; eigenvalue $=3.405$ ), the second dimension was named "Physical Layout and Plan Program Activities" (explained variance = $24 \%$; eigenvalue $=3.118$ ) . The corrected item-total correlation coefficients of the subdimensions items were between .46 - .61; item factor loadings were between .50 and .75 . Two dimensions explained $50 \%$ of the total variance. The Cronbach's alpha coefficients were .82 for "Relationship and Behavior Regulation," .79 for "Physical Layout and Plan Program Activities" sub-dimension, and .86 for the full scale.

\section{Data Analysis}

Descriptive statistics were made by using the SPSS-21 package program. The results showed that the kurtosis and skewness values of the research variables ranged from -.17 to .77. Pearson Product Moment Correlation Coefficient was calculated to analyze the relationships between variables. Multiple Regression Analysis was conducted to determine if the independent variables significantly predicted the dependent variables. Finally, the PROCESS macro based on bootstrap sampling and developed by Hayes (2013) for SPSS was used to analyze teacher self-efficacy's mediating role in the relationships between emotional intelligence and classroom management skills. Confidence intervals were calculated over 5000 resamplings. In the discussions about the significance of the mediating 
effect, it is stated that frequently used methods such as the Sobel $z$ test are based on the normal distribution assumption. However, it is asserted that the Sobel z test will not produce accurate results since the paths $a . b$ described in the Baron and Kenny (1986) model does not have a normal distribution. In this respect, the use of the bootstrap method has become widespread to calculate the mediating effect and standard error (Hayes, 2009; MacKinnon, Lockwood, \& Williams, 2004). In the present study, the PROCESS macro applying the bootstrap method, which has been increasingly seen in both national (Kavgacı \& Çalık, 2017) and international studies (Loflin \& Barry, 2016; Schwarzer, Antoniuk, \& Gholami, 2015), was preferred.

\section{Findings}

In this section, first of all, Pearson Product Moment Correlation Coefficients for the relationships between teachers' emotional intelligence, self-efficacy, and classroom management skills were calculated and presented in Table 1.

Table 1. Findings Regarding the Relationships Between Variables

\begin{tabular}{lccccc}
\hline Variables & 1 & 2 & 3 & 4 & 5 \\
\hline 1. Classroom Management Skills & - & $.89^{* * *}$ & $.89 * * *$ & $.38^{* * *}$ & $.69^{* * *}$ \\
2. Relationship and Behavior Regulation & - & $.58^{* * * *}$ & $.41^{* * *}$ & $.59^{* * *}$ \\
3. Physical Layout and Plan Program Activities & & - & $.26 * * *$ & $.64 * * *$ \\
4. Emotional Intelligence & & & - & $.44 * * *$ \\
5. Teacher Self-Efficacy & & & & - \\
\hline
\end{tabular}

$* * * p<.001$

Findings put forward in Table 1 showed that the relationship between self-efficacy and classroom management skills was stronger than emotional intelligence despite the moderately significant relationship between self-efficacy and emotional intelligence with classroom management skills. Moreover, it was determined that the relationships of the dimension of "Relationship and Behavior Regulation" with independent variables were stronger than the dimension of "Physical Layout and Plan Program Activities." 


\begin{tabular}{|c|c|c|c|c|c|c|c|c|c|}
\hline \multirow[b]{2}{*}{ Variables } & \multicolumn{3}{|c|}{$\begin{array}{c}\text { Physical Layout and } \\
\text { Plan Program } \\
\text { Activities }\end{array}$} & \multicolumn{3}{|c|}{$\begin{array}{c}\text { Relationship and } \\
\text { Behavior Regulation }\end{array}$} & \multicolumn{3}{|c|}{$\begin{array}{c}\text { Classroom } \\
\text { Management Skills } \\
\text { (Total Score) }\end{array}$} \\
\hline & $\beta$ & $t$ & $p$ & $\beta$ & $t$ & $p$ & $\beta$ & $t$ & $p$ \\
\hline $\begin{array}{c}\text { Step } 1 \\
\text { Emotional } \\
\text { Intelligence }\end{array}$ & .26 & 5.25 & .000 & .41 & 8.748 & .000 & .38 & 7.92 & .000 \\
\hline$R^{2}$ & & .07 & & & .17 & & & .14 & \\
\hline$F$ & & 27.542 & .000 & & 76.523 & .000 & & 62.688 & .000 \\
\hline $\begin{array}{c}\text { Step 2 } \\
\text { Emotional } \\
\text { Intelligence }\end{array}$ & -.03 & -.60 & .552 & .19 & 4.073 & .000 & .09 & 2.15 & .032 \\
\hline Self-Efficacy & .65 & 14.572 & .000 & .51 & 11.177 & .000 & .65 & 15.71 & .000 \\
\hline Total $R^{2}$ & & .41 & & & .38 & & & .48 & \\
\hline$\Delta R^{2}$ & & .34 & & & .21 & & & .34 & \\
\hline$F$ & & 127.721 & .000 & & 113.400 & .000 & & 175.398 & .000 \\
\hline$\Delta F$ & & 212.336 & .000 & & 124.922 & .000 & & 246.893 & .000 \\
\hline
\end{tabular}

Table 2 displayed the findings related to the regression analysis. The findings revealed that emotional intelligence alone explained $7 \%$ of the variance in the "Physical Layout and Plan Program Activities" dimension of classroom management skills. However, the self-efficacy variable added in the second step explained $34 \%$ of the variance. They together predicted $41 \%$ of the variance in the "Physical Layout and Plan Program Activities" dimension. When the two variables were considered together, and their contribution to the "Physical Layout and Plan Program Activities" sub-dimension was examined, it was seen that the emotional intelligence became insignificant with the addition of self-efficacy ( $\beta=$ $.03, p>.05)$ into the regression model. However, its contribution to the first step was significant. The contribution of the self-efficacy beliefs to the variance in "Physical Layout and Plan Program Activities" was significant $(\beta=.65, p<.05)$. This indicated that selfefficacy might have a full mediating effect on the relationship between emotional intelligence and the "Physical Layout and Plan Program Activities" dimension; in other 
words, emotional intelligence could indirectly affect the "Physical Layout and Plan Program Activities" dimension through self-efficacy.

The findings relate to the "Relationship and Behavior Regulation," it was revealed that emotional intelligence predicted $17 \%$ of the variance while self-efficacy predicted $21 \%$ if the emotional intelligence variable was controlled. Emotional intelligence and selfefficacy explained $38 \%$ of the variance occurred in the "Relationship and Behavior Regulation" dimension. When two independent variables were handled together, it was seen that self-efficacy $(\beta=.51, p<.05)$ was a stronger predictor than emotional intelligence $(\beta=$ $.19, p<.05)$.

Considering the findings regarding the prediction of the total score on classroom management skills, it was found out that emotional intelligence predicted $14 \%$ of the variance in the classroom management skills, and self-efficacy predicted $34 \%$ when emotional intelligence was controlled. The independent variables added to the model together predict $48 \%$ of the variance in classroom management skills. When the contributions of the two variables to the model were considered together, it was seen that self-efficacy $(\beta=.65, p<.05)$ was a stronger predictor than emotional intelligence $(\beta=.09$, $p$ <.05). The striking point in the findings was that the standardized regression coefficients showing the relationship of emotional intelligence with classroom management skills decreased by more than $50 \%$ with self-efficacy to the model. However, in both steps, emotional intelligence's contribution to the model was significant $(p<.05)$. This suggests that self-efficacy may partially mediate the relationship between emotional intelligence and classroom management skills (Hayes, 2013).

As the research findings pointed to the mediator effect, it was decided that the significance of this mediating effect should be examined. In this context, the significance of mediation was tested by Hayes using the PROCESS macro for SPSS (Hayes, 2013). Since both sub-dimensions and class management skills total score was accepted as dependent variables in the study, mediation analysis was repeated for all three and. Table 3 displays the findings below. 
Table 3. Findings Regarding the Mediation Effect of Self-Efficacy

\begin{tabular}{lccccccccc}
\hline & \multicolumn{2}{c}{$\begin{array}{c}\text { Physical Layout and } \\
\text { Plan Program Activities }\end{array}$} & \multicolumn{2}{c}{$\begin{array}{c}\text { Relationship and } \\
\text { Behavior Regulation }\end{array}$} & \multicolumn{3}{c}{$\begin{array}{c}\text { Classroom Management } \\
\text { Skills (Total Score) }\end{array}$} \\
\hline $\begin{array}{l}\text { Arac1 } \\
\text { Değişken }\end{array}$ & $\beta$ Effect & SE & $\begin{array}{l}\text { LLCI- } \\
\text { ULCI }\end{array}$ & $\beta$ Effect & SE & $\begin{array}{l}\text { LLCI- } \\
\text { ULCI }\end{array}$ & $\beta$ Effect & SE & $\begin{array}{r}\text { LLCI- } \\
\text { ULCI }\end{array}$ \\
\hline $\begin{array}{l}\text { Öz } \\
\text { yeterlik }\end{array}$ & .29 & .03 & $.22-.36$ & .23 & .03 & $.17-.28$ & .29 & .03 & $.23-.35$ \\
\hline
\end{tabular}

An LLCI: Lower Levels for Confidence Interval, ULCI: Upper Levels for Confidence Interval, SE: Standard Error. Standard error and confidence intervals are Bootstrap values.

As can be seen from Table 3, the indirect effect of emotional intelligence on classroom management through self-efficacy was significant $(.29 ; \mathrm{SE}=.03 ; \mathrm{CI}=[.23, .35]$; $p$ <.01). Similarly, the indirect effects of emotional intelligence on "Physical Layout and Plan Program Activities" (.29; SE = .03; CI $=[.22, .36] ; p<.01)$ and "Relationship and Behavior Regulation" (.23; $\mathrm{SE}=.03 ; \mathrm{CI}=[.17, .28] ; p<.01)$ were also significant. In this respect, it was revealed that self-efficacy played a fully mediating role in the relationship between emotional intelligence and the "Physical Layout and Plan Program Activities," and a partial mediating role in other models. Therefore, it can be stated that the mediation situation that emerged in the regression analysis was confirmed. In other words, except for the "Physical Layout and Plan Program Activities" sub-dimension, it was seen that teachers' emotional intelligence positively and significantly affected their classroom management skills both directly and indirectly by strengthening their self-efficacy perceptions related to teaching.

\section{Discussion}

In this part of the research, the research findings related to the research questions were discussed in the related literature. Firstly, the analyses showed that the independent variables were significantly associated with classroom management skills. Considering the relationships between the sub-dimensions of classroom management skills and independent variables, it was found out that the teachers' self-efficacy beliefs had the strongest relationship. A moderate positive significant relationship was found between the "Physical Order and Plan-Program Activities" and "Relationship and Behavior Regulation" dimensions of teachers' self-efficacy beliefs and classroom management skills. However, it was seen that the "Physical Layout and Plan Program Activities" has a stronger relationship 
with self-efficacy than "Relationship and Behavior Regulation." Similarly, in the studies of Babaoğlan and Korkut (2010) and Korkut (2009), it was revealed that the sub-dimensions of classroom management skills were significantly associated with self-efficacy.

The present study revealed that the strongest relationship with classroom management skills was with self-efficacy. According to this mutual relationship, when selfefficacy increases, classroom management skills also increase or vice versa. Since selfefficacy includes the ability to use classroom management systems effectively, to teach courses appropriately to the student level, and have competence in student assessment, its significant relationship with classroom management skills can be theoretically accepted as usual. The teacher-student relationship, behavioral arrangements, time management, the physical order of the classroom, and plan-program activities dimensions of classroom management skills increase teacher's self-confidence, leading to a healthier transfer of information to students increase in self-belief (Başar, 2014). This situation explains the significant relationships between the two variables. When the existing literature is examined, it is seen that the previous studies support this result. For instance, according to Bay (2020), Özçelik (2019), Semerci and Uyanık Balat (2018), and Bozbaş (2015), there was a significant relationship between classroom management skills and self-efficacy beliefs.

Similarly, Çelik (2019) found a significant relationship between classroom management levels and self-efficacy levels. Özbezek and Paksoy (2017) found a significant relationship between students' leadership motivation and self-efficacy. According to Güneş (2016), a teacher's self-efficacy is an important sign of his/her leadership in teaching. In parallel with these findings, Porter (2011) stated that those with high self-efficacy were more likely to lead because they liked to take leadership roles. Teachers' self-efficacy is an important factor for effective teaching. The teacher's performance who feels self-sufficient in the classroom will increase, which will contribute to the decrease of negative factors that can be experienced in the classroom. Therefore, the increase in teachers' self-efficacy can contribute to their success in classroom management skills.

According to the study's findings, the other variable that significantly correlated with classroom management skills was emotional intelligence. When the existing literature was examined, significant relationships can be found between the sub-dimensions of classroom management skills and emotional intelligence (Karagözoğlu, 2016; Köprülü et al., 2018). Considering the elements that form the classroom management skills, it can be revealed that the focus is on the communication and relationship with the students in the classroom. 
Interpersonal relationship management generally focuses on recognizing, understanding, interpreting, and controlling emotions. Therefore, it can be said that the teacher who does not realize his/her or his/her students' feelings and emotions does or have the necessary competence for teaching. Emotional intelligence includes the skills of "recognizing and managing one's own emotions, being aware of the others' emotions, and managing social relations" (Tuyan \& Beceren, 2004, p.38). George (2000) suggested that emotional intelligence, in other words, the ability to understand and manage one's own and others' moods and emotions, contributed to effective leadership in organizations. Similarly, Rosete and Ciarrochi (2005) stated that stronger emotional intelligence and leadership were related. In parallel with the studies, Acar (2002) emphasized a positive relationship between emotional intelligence and leadership behaviors. Additionally, teachers with high emotional intelligence could raise healthy generations by strengthening their relationship with their students and increasing their students' self-confidence. Therefore, it can be said that the teacher's competence in management skills overlaps with the elements that form emotional intelligence. Teachers with high classroom management skills are expected to use their time efficiently. They also ensure that children receive an education free from stress, sharing, effectiveness, and tolerance. Similarly, another research (Tunca, 2010) found out positive correlations between teachers' classroom management skills and their level of optimism/mood regulation, which is one of the sub-dimensions of emotional intelligence. Teachers should consider situations such as helping children convey their feelings and learn to share while using classroom management skills (Denizel Güven \& Cevher (2005). In this sense, it can be theoretically expected that emotional intelligence and classroom management skills are significantly and positively related. Özdevecioğlu et al. (2014) found that emotional intelligence diminished or eliminated the negative effect of malicious management perception on employees. The findings of the current study also revealed that teachers' emotional intelligence and their classroom management skills were positively correlated. It is also thought that processes such as recognizing and managing emotions can become more effective with training. For example, Köprülü et al. (2018) stated that the academic staff who received emotional intelligence training had higher classroom management skill scores than those who did not.

There is a moderate, positive, and significant relationship between self-efficacy and emotional intelligence. In other words, the strengthening of an individual's emotional intelligence indicates that his/her self-efficacy also improves. Therefore, the emergence of a 
positive and significant relationship between self-efficacy and emotional intelligence is theoretically understandable. The existing literature also showed significant positive relationships between emotional intelligence and self-efficacy (Abdolvahabi et al., 2012; Amirian \& Behshad, 2016; Çelik Ağırman \& Naktiyok, 2018; Di Fabio \& Palazzeschi, 2008; Hashemi \& Ghanizadeh, 2011 ; Karamehmetoğlu, 2017; Öcal \& Şenel, 2016; Özbezek \& Paksoy, 2017; Ramchunder \& Martins, 2014; Rastegar \& Memarpour, 2009; Sert \& Shave, 2019; Sarkhosh \& Rezaee, 2014; Şenel, 2015; Şenel et al., 2014; Wu et al., 2019). For example, according to Hashemi and Ghanizadeh (2011), it was found that selfactualization and stress tolerance were positive predictors of students' self-efficacy among the emotional intelligence components. When considered in terms of teachers, it can be thought that a teacher who is self-actualized and has high-stress tolerance will have more power to explain their self-efficacy levels. Sert and Traş (2019) revealed significant relationships between emotional and academic self-efficacy and the sub-dimensions of emotional intelligence, and social self-efficacy, and some dimensions of emotional intelligence. There are also findings indicating positive relationships between emotional intelligence and self-efficacy and leadership effectiveness (Ramchunder \&Martins, 2014).

The current research showed that emotional intelligence and self-efficacy positively predicted classroom management skills. When the predictive power of emotional intelligence on sub-dimensions of classroom management skills was examined, it was seen that it predicted the "Physical Layout and Plan Program Activities" sub-dimension less than others. With the addition of self-efficacy into the model, it was observed that the predictive power of the model for the "Physical Layout and Plan Program Activities" sub-dimension increased. However, it caused emotional intelligence's effect on the "Physical Layout and Plan Program Activities" to decrease its significance. "Physical Layout and Plan Program Activities" is a dimension that requires not using emotions, but rather an objective belief of the individual's competencies in this matter. Therefore, the decreasing effect of emotional intelligence in the model, whereas the increasing total is predicting power of the model with self-efficacy, can be seen as acceptable theoretically. This indicates that self-efficacy may have a fully mediating role in this relationship (Hayes, 2013).

When the "Relationship and Behavior Regulation" sub-dimension of classroom management skills was examined, it was seen that in the first step, emotional intelligence alone predicted less the change in the "Relationship and Behavior Regulation" subdimension. However, when self-efficacy was added, the predictive power of the model 
increased. Moreover, with the addition of self-efficacy to the model, it was observed that the predictive power of the emotional intelligence on the variance in the "Relationship and Behavior Regulation" decreased, but its contribution was still significant. It is thought that this significant ongoing effect may be a result of a common ground for both variables. That is to say, both the "Relationship and Behavior Regulation" and emotional intelligence are affected mostly by human factors, in other words, human relationships, and this commonality can help this effect to continue.

As a final step for the regression analysis, the independent variables' ability to explain the total classroom management skills was. According to the current research findings, it can be inferred that teachers with high emotional intelligence strengthen the teacher-student relationship, increase the student's self-confidence, and raise healthy generations. It is seen that previous studies support this inference (Çakar \& Arbak, 2003; Delice \& Günbeyi, 2013; Tunca, 2010; Summak \& Özgan, 2007). According to Çakar and Arbak (2003), the administers with higher emotional intelligence tend to see the audience as an individual rather than as members of the group and take more care of their staff's problems. At the same time, it is known that administrators with higher emotional intelligence are more inspirational to their employees. The relationship between administrators and workers stated in this study can be thought of as the relationship between teacher and students. In the study of Delice and Günbeyi (2013), it was revealed that the general mood and personal awareness dimension predicted the leadership behaviors. According to Summak and Özgan (2007), it was observed that some emotional, social, and spiritual intelligence competencies of the administrators predicted the administrative process skills. The studies' common point was that emotional intelligence gave a positive meaning to the administration and leadership processes. Therefore, these findings are in line with current research results. With the addition of self-efficacy to the model, it was seen that the predictive power of the independent variables increased together. In other words, emotional intelligence seems to be efficient, and this strengthens self-efficacy. Another important point related to the findings was that the contribution of emotional intelligence to the model was significant. The standardized regression coefficients showing their relationship with classroom management skills decreased more than half with self-efficacy addition to the model. This pointed out that self-efficacy could partially mediate the relationship between emotional intelligence and classroom management skills. In other words, emotional 
intelligence could indirectly affect classroom management skills via self-efficacy (Baron \& Kenny, 1986; Hayes, 2013).

The prediction of the variance in the classroom management skills by self-efficacy and emotional intelligence shows that the increase in teachers' self-efficacy and emotional intelligence explains the increase in classroom management skills. In this case, it can be said that teachers with high emotional intelligence and self-efficacy beliefs are also successful in classroom management. Therefore, it is easier for them to reach the goals they aim for in the classrooms, thus improving teaching and learning. It is seen that the results of the research conducted are in line with the existing literature. Classroom management skills of faculty members who had received emotional intelligence training were higher than those who did not (Köprülü et al., 2018).

Furthermore, there was a positive relationship between emotional intelligence and leadership behavior (Acar, 2002), and instructional leadership predicted self-efficacy (Sığrı, Tabak, \& Güngör, 2012). Karamehmetoğlu (2017) also showed that emotional intelligence was a predictor of classroom management self-efficacy. Considering the findings of the regression analysis, it can be said that the related study is consistent with the present one.

The current study found out that the indirect effect of emotional intelligence on classroom management via self-efficacy was stronger than its direct effect. The existing literature showed that emotional intelligence strengthened self-efficacy (Hashemi \& Ghanizadeh, 2011; Karamehmetoğlu, 2017). Contrary to this study, according to Özbezek and Paksoy (2017), the mediating role of self-efficacy in the relationship between emotional intelligence and motivation to lead was not significant. But the participants of Özbezek and Paksoy's study were students, which could be one reason for this result.

The current research is limited to teachers working in public schools affiliated with the Kastamonu Directorate of National Education. Based on the results of the research, the following suggestions are given for researchers and practitioners:

1) In the study, the predictive level of self-efficacy and emotional intelligence on classroom management skills and the mediating role of self-efficacy were examined. Models with more variables should be tested for the other classroom management that cannot be explained yet. In this respect, it can be suggested to test the relationships and mediating roles by adding organizational variables such as the school climate, which encompasses all 
stakeholders of the school participating in the school's administrative and educational activities, in addition to personal variables.

2) It has been observed that quantitative research methods are mostly used in the existing literature. Different studies on classroom management skills, emotional intelligence, and self-efficacy can be conducted using qualitative research methods.

3) Emotional intelligence and self-efficacy beliefs were found to be determinant variables in classroom management skills. For this reason, more pre-service and in-service training activities that strengthen these characteristics of teachers can be provided.

4) As part of their leadership duties, school administrators can encourage teachers to present new ideas for improving teaching processes and school culture to support their selfefficacy beliefs and emotional intelligence.

Ethical Approval: This article has been produced from the thesis "Examining the Relationship Between Teachers' Emotional Intelligence and Self-Efficacy Beliefs and Classroom Management Skills" prepared under the supervision of Hasan KAVGACI. (Thesis No: 534921). A part of the study was presented as an oral presentation at the 27th International Educational Sciences Congress between 18-22 April 2018.

Conflict Interest: The authors do not declare any conflict of interest.

Authors Contributions: Both authors contributed equally to this article. 


\section{References}

Abdolvahabi, Z., Bagheri, S., Haghighi, S., \& Karimi, F. (2012). Relationship between emotional intelligence and self-efficacy in practical courses among physical education teachers. European Journal of Experimental Biology, 2(5), 1778-1784.

Abu Tineh, A. M., Khasawneh, S. A. \& Khalaileh, H. A. (2011). Teacher self-efficacy and classroom management styles in Jordanian schools. Management in Education, 25(4), 175-181. doi: 10.1177 / 0892020611420597

Acar, F. (2002). Duygusal zekâ ve liderlik. Erciyes Üniversitesi Sosyal Bilimler Enstitüsü Dergisi, 12(12), 53-68.

Akgemci, T. \& Doğanalp, B. (2008). Duygular ve liderlik: Duygusal zekânın rolü. M.Ş. Şimşek, A. Çelik (Ed.). Çă̆daş yönetim ve örgütsel başarım içinde (s.185-206). Konya: Eğitim Kitabevi Yayınları.

Aksoy, R. (2011). Ortaöğretim ögretmenlerinin ögretmen öz yeterlik ve yapılandırmact ögrenme ortamı düzenleme becerilerine yönelik algıları (Manisa ili örneği). (Yüksek lisans tezi). Yükseköğretim Kurulu Ulusal Tez Merkezi’nden edinilmiştir (Tez No: 326003).

Amirian, S. M. R. \& Behshad, A. (2016). Emotional intelligence and self-efficacy of Iranian teachers: A research study on university degree and teaching experience. Journal of Language Teaching and Research, 7(3), 548-558. doi: http://dx.doi.org/10.17507/jltr.0703.16

Babaoğlan, E. \& Korkut, K. (2010). Sınıf öğretmenlerinin öz yeterlik inançları ile sınıf yönetim beceri algıları arasındaki ilişki. İnönü Üniversitesi Eğitim Fakültesi Dergisi, 11(1), 1-19.

Baloğlu, N. (2001). Etkili sınıf yönetimi. Ankara: Baran Ofset Matbaacılık.

Bandura, A. (1982). Self-efficacy mechanism in human agency. American Psychologist, 37(2), 122-147. doi https://doi.org/10.1037/0003-066X.37.2.122

Baron, R. M. \& Kenny, D. A. (1986). The moderator-mediator variable distinction in social psychological research: Conceptual, strategic, and statistical considerations. Journal of Personality and Social Psychology, 51, 1173-1182. doi: 10.1037 // 00223514.51.6.1173 
Bar-On, R. (2006). The Bar-On model of emotional-social intelligence (ESI). Psicothema, $18(1), 13-25$.

Başar, H. (2014). Sınıf yönetimi. Ankara: Anı Yayıncılık.

Batar, M. \& Aydın, İ. S. (2014). Türkçe öğretmeni adaylarının yazılı anlatım öz yeterlik inançlarının değerlendirilmesi. International Journal of Language Academy, 2(4), 579-598.

Bay, D. N. (2020). Investigation of the relationship between self-efficacy belief and classroom management skills of preschool teachers with other variables. International Electronic Journal of Elementary Education, 12(4), 335-348. doi:10.26822/iejee.2020459463

Bozbaş, Y. (2015). Sınıf öğretmenlerinin öz yeterlilik inançlarl ve sınıf yönetimi beceri algıları arasındaki ilişki (Yüksek lisans tezi). Yükseköğretim Kurulu Ulusal Tez Merkezi'nden edinilmiştir (Tez No: 407057).

Çakar, U. \& Arbak, Y. (2003). Dönüşümcü liderlik duygusal zekâ gerektirir mi? Yöneticiler üzerinde örnek bir çalışma. Dokuz Eylül Üniversitesi İktisadi İdari Bilimler Fakültesi Dergisi, 18(2), 83-98.

Çapa, Y., Çakıroğlu, J., \& Sarıkaya, H. (2005). The developmeı1t and validation of a Turkish version of the teachers' sense of efficacy scale. Education and Science, 30(137), 7481.

Çelik Ağırman, Ü. H. \& Naktiyok, A. (2018). Öz yeterlilik algısı bağlamında duygusal zekâ özellikleri ve girişimcilik niyeti. Journal of Social and Humanities Sciences Research, 5(28), 3253-3262.

Çelik, O. (2019). İlkokul ve ortaokul öğretmenlerinin öz yeterlilikleri ile sınıf yönetimi becerileri arasındaki ilişkinin incelenmesi (Yüksek lisans tezi). Yükseköğretim Kurulu Ulusal Tez Merkezi’nden edinilmiştir (Tez No: 553475).

Çelik, V. (2013). Sınıf yönetimi. Ankara: Nobel Yayın Dağıtım.

Delice, M. \& Günbeyi, M. (2013). Duygusal zekâ ve liderlik ilişkisinin incelenmesi: Polis teşkilatı örneği. Atatürk Üniversitesi İktisadi ve İdari Bilimler Dergisi, 27(1), 209239. 
Delson, K. M. (1982). A three dimensional approach to evaluating teaching performance, Paper presented At The Annual Convention Of The American Council On The Teaching For Foreign Languages, New York.

Demir, T. (2015). Okul öncesi ögretmenlerinin öz yeterlik algllarının ve sınıf yönetimi stratejilerinin çocuk-öğretmen ilişkileri üzerindeki etkileri (Yüksek lisans tezi). Yükseköğretim Kurulu Ulusal Tez Merkezi’nden edinilmiştir (Tez No: 423431).

Demirtaş, H. (2015). Sınıf yönetiminin temelleri. H. Kıran ve K. Çelik (Ed.) içinde, Etkili sınıf yönetimi (s. 1-32). Ankara: Anı Yayıncılık.

Deniz, M. E., Özer, E., \& Işık, E. (2013). Duygusal zekâ özelliği ölçeği-kısa formu: Geçerlik ve güvenirlik çalışması. Eğitim ve Bilim, 38(169), 407-419.

Denizel Güven, E. \& Cevher, F. N. (2005). Okulöncesi öğretmenlerinin sınıf yönetim becerilerinin çeşitli değişkenler açısından incelenmesi. Pamukkale Üniversitesi Ĕ̈itim Fakültesi Dergisi, 2(18), 1-22.

Di Fabio, A. \& Palazzeschi, L. (2008). Emotional intelligence and self-efficacy in a sample of Italian high school teachers. Social Behavior and Personality, 36(3), 315-326. doi: 10.2224 / sbp.2008.36.3.315

Eker, C. (2014). Sınıf öğretmenlerinin öz yeterlik inanç düzeyleri üzerine bir araştırma. Uşak Üniversitesi Sosyal Bilimler Dergisi, 7(1), 162-178.

Epstein, A. \& Willhite, G. L. (2015). Teacher efficacy in an early childhood professional development school. International Electronic Journal of Elementary Education, 7(2), 189-198.

Erdoğan, İ. (2015). Sınıf yönetimi: Ders, konferans panel ve seminer etkinliklerinde başarının yolları. İstanbul: Alfa Basım Yayım Dağıtım.

Geçikli, F. (2013). Halkla ilişkiler ve iletişim. İstanbul: Beta Yayıncılık.

George, J. M. (2000). Emotions and leadership: The role of emotional intelligence. Human Relations, 53(8), 1027-1055. doi:10.1177/0018726700538001

Goleman, D. (2010). Duygusal zekâ (EQ), neden IQ'dan daha önemlidir? (B.Seçkin Yüksel Çev.). İstanbul: Varlık Yayınları. 
Goleman, D., Benett, L., \& Barlow, Z. (2012). Ecoliterate: How educators are cultivating emotional, social and ecological intelligence. SanFrancisco: Jossey-Bass. http://ebookcentral.proquest.com adresinden alınmıştır.

Grant, C. A. \& Gillette, M. (2006). A candid talk to teacher educators about effectively preparing teachers who can teach everyone"s children. Journal of Teacher Education, 57(3), 292-299. doi: 10.1177 / 0022487105285894

Gültekin, M. (2020). Değişen toplumda eğitim ve öğretmen nitelikleri. Anadolu Journal of Educational Sciences International, 10(1), 654-700. doi: 10.18039/ajesi.682130

Güneş, A. M. (2016). Sınıf ögrretmenlerinin sınıf yönetim becerileri, teknoloji kullanımları ve öz yeterlik inançları arasındaki ilişki (Doktora tezi). Yükseköğretim Kurulu Ulusal Tez Merkezi’nden edinilmiştir (Tez No: 450126).

Hashemi, M. R. \& Ghanizadeh, A. (2011). Emotional intelligence and self-efficacy: A case of Iranian EFL University students. International Journal of Linguistics, 3(1), 1-16. doi: 10.5296/ijl.v3i1.877

Hayes, A. F. (2013). Introduction to mediation, moderation, and conditional process analysis: A regression-based approach. New York, NY: The Guilford Press.

Hoy, W. K. \& Miskel, C. G. (2012). Eğitim yönetimi: Teori, araştırma ve uygulama (S. Turan Çev. Ed.). Ankara: Nobel Akademi Yayınları.

İpek, S. \& İpek, C. (2015). Temel eğitimde görev yapan öğretmenlerin sınıf yönetimi öz yeterlik inançları ve mesleki tutumları. (Rize ili örneği), EJEDUS Elektronik Ĕ̆itim Bilimleri Dergisi, 4(8), 169-190.

Karagözoğlu, N. (2016). Sosyal bilgiler öğretmenlerinin duygusal zekâ yeterliklerini mesleğinde kullanma düzeyleri ile benimsedikleri sınıf yönetim modelleri arasındaki ilişki. Akademik Sosyal Araştırmalar Dergisi, 4(29), 269-287. doi: 10.16992/ASOS.1240

Karamehmetoğlu, M. (2017). Beden eğitimi öğretmenlerinin duygusal zekâ düzeylerinin mesleki öz yeterlik ve problem çözme becerilerini belirlemedeki rolünün incelenmesi (Yüksek lisans tezi). Yükseköğretim Kurulu Ulusal Tez Merkezi’nden edinilmiştir (Tez No: 469599). 
Kavgacı, H. (2014). İlköğretim kurumu öğretmenlerinin işle bütünleşme düzeylerinin bireysel ve örgütsel değişkenlerle ilişkisi (Doktora tezi). Yükseköğretim Kurulu Ulusal Tez Merkezi'nden edinilmiştir (Tez No: 366266).

Kavgacı, H. \& Çalık, T. (2017). Öğretmenlerin işle bütünleşme düzeylerinin örgütsel ve bireysel değişkenlerle ilişkisi: Bir çoklu aracılık modeli. Kuram ve Uygulamada Ĕ̌itim Yönetimi, 23(2), 223-248. doi: 10.14527/kuey.2017.008

Koçoğlu, Z. (2011). Emotional intelligence and teacher efficacy: A study of Turkish EFL pre-service teachers. Teacher Development, 15(4), 471-484. doi: 10.1080/13664530.2011.642647

Korkmaz, İ. (2013). Sosyal öğrenme kuramı. B. Yeşilyaprak (Ed.). Eğitim psikolojisi: Gelişim-ögrrenme-ögretim içinde (s. 245 - 270). Ankara: Pegem Akademi Yayıncılık.

Korkut, K. (2009). Sını öğretmenlerinin öz yeterlik inançları ile sınıf yönetim beceri algıları arasındaki ilişki (Yüksek lisans tezi). Yükseköğretim Kurulu Ulusal Tez Merkezi'nden edinilmiştir (Tez No: 250873).

Köprülü, O., Turhan, M., \& Helvac1, İ. (2018). Öğretim elemanları ve öğretmenlerin duygusal zekâ düzeyleri ve sınıf yönetim becerileri açısından karşılaştırılması. The Journal of Academic Social Science Studies, 71, 419-426. doi: http://dx.doi.org/10.9761/JASSS7735

Loflin, D. C. \& Barry, C. T. (2016). 'You can't sit with us:' Gender and the differential roles of social intelligence and peer status in adolescent relational aggression. Personality and Individual Differences, 91, 22-26. doi: https://doi.org/10.1016/j.paid.2015.11.048

Luthans, F. (2002). Positive organizational behavior: Developing and managing psychological strengths. The Academy of Management Executive, 16(1), 57-75.

MacKinnon, D. P., Lockwood C. M., \& Williams, J. (2004). Confidence limits for the indirect effect: Distribution of the product and resampling methods. Multivariate Behavioral Research, 39(1), 99-128. doi: 10.1207 / s15327906mbr3901_4

Milli Eğitim Bakanlığı (MEB), (2017). Öğretmenlik mesleği genel yeterlikleri. Ankara: Öğretmen Yetiştirme ve Geliştirme Genel Müdürlüğü. http://oygm.meb.gov.tr/www/ogretmenlik-meslegi-genel-yeterlikleri/icerik/39 adresinden alınmıştır. 
Öcal, K. \& Şenel, E. (2016). Duygusal zekânın sosyal destek algısı üzerindeki etkisi: Öz yeterlik inancının aracı rolü. Sosyal ve Beceri Bilimler Araştırmaları Dergisi, 17(36), 138-154.

Özbezek, B. D. \& Paksoy, H. M. (2017). Liderlik etme motivasyonu ve duygusal zekâ arasındaki ilişkide öz yeterliliğin rolü üzerine bir araştırma. International Journal of Disciplines Economics \& Administrative Sciences Studies, 3(4), 248-269.

Özçelik, F. (2019). Okul öncesi ögretmenlerinin sınıf yönetimi becerileri ile öz yeterlikleri arasındaki ilişki (Yüksek lisans tezi). Yükseköğretim Kurulu Ulusal Tez Merkezi'nden edinilmiştir (Tez No: 563079).

Özdevecioğlu, M., Akın, M. Karaca, M., \& İştahlı, B. (2014). Kötü niyetli yönetim algılamasının çalışanların performansları üzerindeki etkisinde duygusal zekânın rolü. Çankırı Karatekin Üniversitesi İktisadi ve İdari Bilimler Fakültesi Dergisi, 4(1), 118.

Petrides, K. V. \& Furnham, A. (2001). Trait emotional intelligence: Psychometric investigation with reference to established trait taxonomies. European Journal of Personality, 15(6), 425-448. doi: 10.1002 / per. 162

Porter, T. H. (2011). The power of transformational leadership: The effect on self-efficacy, spirituality, and MTL (Doctoral dissertation). Retrieved from ProQuest Dissertations and Theses database. (UMI: 3480381).

Ramchunder, Y., \& Martins, N. (2014). The role of self-efficacy, emotional intelligence and leadership style as attributes of leadership effectiveness. SA Journal of Industrial Psychology, 40(1), 1-11. doi: http://dx.doi.org/10.4102/sajip.

Rastegar, M. \& Memarpour, S. (2009). The relationship between emotional intelligence and self-efficacy among Iranian EFL teachers. Science Direct, 37, 700-707.

Robbins, S. P. \& Judge, T. A. (2015). Örgütsel davranış (İ.Erdem Çev,Ed.). Ankara: Nobel Akademik Yayınc1lık.

Rosete, D. \& Ciarrochi, J. (2005). Emotional intelligence and its relationship to workplace performance outcomes of leadership effectiveness. Leadership \& Organization Development Journal, 26(5), 388-399. doi: 10.1108/01437730510607871

Ross, J. A. (1992). Teacher efficacy and the effects of coaching on student achievement. Canadian Journal of Education, 17(1), 51-65. 
Salovey, P. \& Mayer, J. D. (1990). Emotional intelligence. Imagination, cognition and personality, 9(3), 185-211. doi: https://doi.org/10.2190\%2FDUGG-P24E-52WK$6 \mathrm{CDG}$

Sarıtaş, M. (2003). Sınıf yönetimi ve disiplinle ilgili kurallar geliştirme. L. Küçükahmet (Ed.). Sınıf Yönetiminde Yaklaşımlar içinde (s.43-86). Ankara: Nobel Yayın Dağıtım.

Sarkhosh, M. \& Rezaee, A. A. (2014). How does university teachers' emotional intelligence relate to their self-efficacy beliefs? Porta Linguarum, 21, 85-100.

Schwarzer, R., Antoniuk, A., \& Gholami, M. (2015). A brief intervention changing oral selfcare, self-efficacy, and self-monitoring. British Journal of Health Psychology, 20, 56-67. doi: 10.1111/bjhp.12091

Semerci, D. \& Uyanık Balat, G. (2018). Okul öncesi öğretmenlerinin sınıf yönetimi becerileri ve öz yeterlik algıları arasındaki ilişkinin incelenmesi. İnönü Üniversitesi Ĕ̌itim Fakültesi Dergisi, 19(3), 494-514. doi: 10.17679/inuefd.394585

Senemoğlu, N. (2013). Gelişim, ögrenme ve öğretim: Kuramdan uygulamaya. Ankara: Yargı Yayınevi.

Sert, M. \& Traş, Z. (2019). Ergenlerin duygusal zekâ düzeyleri ile öz yeterlik algıları arasındaki ilişkinin incelenmesi. Manas Sosyal Araştırmalar Dergisi, 8(1), 12391254. doi: https://doi.org/10.33206/mjss.500797

Sığrı, Ü., Tabak, A., \& Güngör, H. (2012). Öz yeterliğin dönüştürücü liderlik üzerine etkisi: Kamu sektöründe bir araştırma. Istanbul Ticaret Üniversitesi Sosyal Bilimler Dergisi, 9(17), 51-66.

Summak, M. S. \& Özgan, H. (2007). İlköğretim okulu müdürlerinin yönetim süreçlerini kullanma etkinlikleri ile bazı duygusal sosyal ve ruhsal yeterlilikleri arasındaki ilişkinin incelenmesi (Kilis ili örneği). Türk Ĕ̆itim Bilimleri Dergisi, 5(2), 261-288.

Şenel, E. (2015). Beden ĕgitimi ve spor yüksekokulunda öğrenim gören ögrrencilerin sosyal destek algıları, genel öz yeterlik inançları ve duygusal zekâ düzeylerinin değerlendirilmesi (Yüksek lisans tezi). Yükseköğretim Kurulu Ulusal Tez Merkezi’nden edinilmiştir (Tez No: 419983).

Şenel, E., Adiloğulları, İ., \& Ulucan H. (2014). Examination of emotional intelligence level, teacher's self-efficacy beliefs and general self-efficacy beliefs of teachers. Nigde University Journal of Physical Education and Sport Sciences, 8(2), 22-232. 
Taş, A. (2015). Sınıf yönetimini etkileyen faktörler. H. Kıran ve K. Çelik (Eds.). Etkili Sınıf Yönetimi içinde (s.33-58). Ankara: Anı Yayıncılık.

Tok, T. N., Tok Ş., \& Doğan Dolapçioğlu, S. (2013). The relationship between emotional intelligence and classroom management approaches of primary school teachers. Educational Research, 4(2), 134-142. doi: 10.1002/pits.22218

Toytok, E. H. (2013). Öğretmenlerin duygusal zekâ yeterliklerini sınıf yönetimi sürecinde kullanma düzeyleri: Sakarya ili örneği. Anadolu Ĕ̆itim Liderliği ve Öğretim Dergisi, l(1), 27-43.

Tschannen-Moran, M. \& Hoy, A. W. (2001). Teacher efficacy: Capturing and elusive construct. Teaching and Teacher Education, 17(7), 783-805. doi: 10.1016/S0742051X(01)00036-1

Tschannen-Moran, M., Woolfolk Hoy, A., \& Hoy, W. K. (1998). Teacher efficacy: Its meaning and measure. Review of Educational Research, 68(2), 202-248. doi: $10.3102 / 00346543068002202$

Tunca, Ö. (2010). Duygusal zekâ düzeylerinin sınıf yönetim becerilerine etkisi ve bir araştırma (Yüksek lisans tezi). Yükseköğretim Kurulu Ulusal Tez Merkezi’nden edinilmiştir (Tez No: 264508).

Tuyan S. \& Beceren, E. (2004). Sınıf yönetiminde duygusal zekâ becerilerinin kullanılması. Çukurova Üniversitesi Ĕ̆itim Fakültesi Dergisi, 2(28), 37-42.

Türk Eğitim Derneği (TED). (2009). Öğretmen yeterlikleri. Ankara: Adım Okan.

Üredi, I. \& Üredi, L. (2006). Sınıf öğretmeni adaylarının cinsiyetlerine, bulundukları sınıflara ve başarı düzeylerine göre fen öğretimine ilişkin öz yeterlik inançlarının karşılaştırılması. Yeditepe Üniversitesi Ĕ̈itim Fakültesi Dergisi, 1(2), 1-8.

Valente, S., Veiga-Branco, A., Rebelo, H., Lourenço, A. A., \& Cristóvão, A. M. (2020). The relationship between emotional intelligence ability and teacher efficacy. Universal Journal of Educational Research, 8(3), 916-923. doi: 10.13189/ujer.2020.080324

Woolfolk Hoy, A. \& Spero, R. B. (2005). Changes in teacher efficacy during the early years of teaching: A comparison of four measures. Teaching and Teacher Education, 21, 343-356. 
Wu, Y., Lian, K., Hong, P., Liu, S., Lin, R., \& Lian, R. (2019). Teachers' emotional intelligence and self-efficacy: Mediating role of teaching performance. Social Behavior and Personality: An international journal, 47(3), e7869. https://doi.org/10.2224/sbp.7869

Yalçınkaya, M. \& Tonbul, Y. (2002). İlköğretim okulu sınıf öğretmenlerinin sınıf yönetim becerilerine ilişkin alg1 ve gözlemleri. Ege Ĕgitim Dergisi, 1(2), 96-103.

Yüksel, A. (2013). Sinıf ögretmenlerinin sinıf yönetim becerilerinin değerlendirilmesi (Afyonkarahisar ili örneği) (Doktora tezi). Yükseköğretim Kurulu Ulusal Tez Merkezi’nden edinilmiştir (Tez No: 349099). 